University of Louisville ThinkIR: The University of Louisville's Institutional Repository

Electronic Theses and Dissertations

$8-2019$

\title{
Determining the effect of an educational intervention on medical support personnel's knowledge to administer a standardized developmental screening tool.
}

Leslie Chiaventone Lopez

University of Louisville

Follow this and additional works at: https://ir.library.louisville.edu/etd

Part of the Public Health Commons

\section{Recommended Citation}

Lopez, Leslie Chiaventone, "Determining the effect of an educational intervention on medical support personnel's knowledge to administer a standardized developmental screening tool." (2019). Electronic Theses and Dissertations. Paper 3285.

https://doi.org/10.18297/etd/3285

This Doctoral Dissertation is brought to you for free and open access by ThinkIR: The University of Louisville's Institutional Repository. It has been accepted for inclusion in Electronic Theses and Dissertations by an authorized administrator of ThinkIR: The University of Louisville's Institutional Repository. This title appears here courtesy of the author, who has retained all other copyrights. For more information, please contact thinkir@louisville.edu. 


\title{
DETERMINING THE EFFECT OF AN EDUCATIONAL INTERVENTION ON MEDICAL SUPPORT PERSONNEL'S KNOWLEDGE TO ADMINISTER A STANDARDIZED DEVELOPMENTAL SCREENING TOOL
}

\author{
By \\ Leslie Chiaventone Lopez \\ B.S., Southern Illinois University, 2002 \\ M.S., Southern Illinois University, 2004

\begin{abstract}
A Dissertation
Submitted to the Faculty of the

School of Public Health and Informational Sciences of the University of Louisville in Partial Fulfillment of the Requirements

for the Degree of
\end{abstract} \\ Doctor of Philosophy \\ in Public Health Sciences \\ Department of Health Promotion and Behavioral Sciences \\ University of Louisville \\ Louisville, Kentucky
}

August 2019 
Copyright 2019 by Leslie Chiaventone Lopez

All rights reserved 



\title{
DETERMINING THE EFFECT OF AN EDUCATIONAL INTERVENTION ON MEDICAL SUPPORT PERSONNEL'S KNOWLEDGE TO ADMINISTER A STANDARDIZED DEVELOPMENTAL SCREENING TOOL
}

\author{
By \\ Leslie Chiaventone Lopez \\ B.S., Southern Illinois University, 2002 \\ M.S., Southern Illinois University, 2004 \\ A Dissertation Submitted on
}

July 12, 2019

by the following Dissertation Committee:

Richard W. Wilson, DHSc, Dissertation Committee Chair

Veronnie F. Jones, MD, PhD, MSPH, Committee Member

Deborah Winders Davis, PhD, Committee Member

Patricia Gail Williams, MD, Committee Member 


\begin{abstract}
DETERMINING THE EFFECT OF AN EDUCATIONAL INTERVENTION ON MEDICAL SUPPORT PERSONNEL'S KNOWLEDGE TO ADMINISTER A STANDARDIZED DEVELOPMENTAL SCREENING TOOL
\end{abstract}

\author{
Leslie C. Lopez
}

July 12, 2019

Early treatment of developmental delays leads to improved outcomes for children (Yeung et al., 2014). In order to benefit from early intervention, children with developmental delays must be identified and referred at a young age. Although the use of validated developmental screening tools is supported by American Academy of Pediatrics (AAP) guidelines, these instruments are used variably by general physicians in pediatric practice (King et al., 2010). Because of the expanding work roles of medical support personnel, it is worthwhile to determine if this group can administer and score a developmental screening tool after completing an educational intervention to assist general pediatric practices in using these tools in accordance with the AAP mandate. Currently, no peer-reviewed published research exists regarding training medical support personnel to administer and score a standardized developmental screening tool. Guided by Kirkpatrick's four-level evaluation model, the current mixed methods study sought to: 1) assess the effect of an educational intervention on the knowledge of medical support 
personnel in pediatric primary care settings to administer and score a standardized developmental screening tool; 2) determine if the medical support personnel were able to score the selected tool in practice as accurately as the "gold standard"; and 3) report the experience of medical support personnel learning and applying a newly acquired skill in clinical practice. Study participants from three urban pediatric clinics completed a preand post-survey and an educational intervention. One participant from each clinic also completed an in-depth interview to describe their experience with the educational intervention and the application of the learned information in practice. Quantitative data analysis indicated that after the educational intervention, the medical support personnel demonstrated a significant increase $(\mathrm{p}<.020)$ on knowledge posttest scores (mean 16.69, SD 2.898) from pre-test scores (mean 14.46, SD 2.961). The medical support personnel were also mostly successful in administering and scoring the developmental screener in practice (80\%). Qualitatively, study participants indicated that the educational intervention was acceptable, and positively impacted their practice. This project demonstrates that an educational intervention increased the knowledge of medical support personnel regarding developmental screening. 
TABLE OF CONTENTS

ABSTRACT ......................................................................

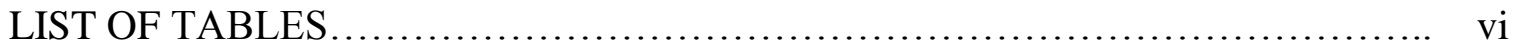

CHAPTER ONE .............................................................. 1

ORGANIZATION OF STUDY ...................................... 30

CHAPTER TWO ................................................................... 33

METHODS............................................................. 40

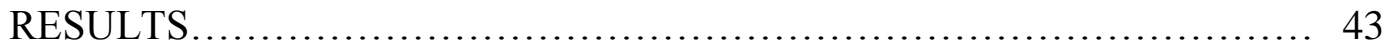

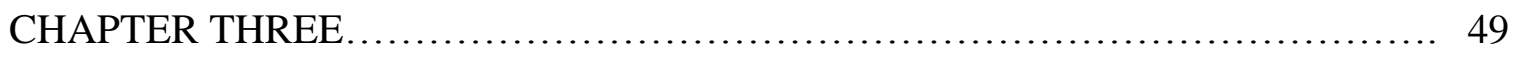

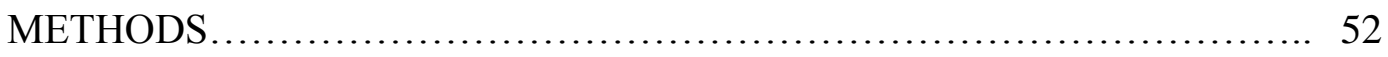

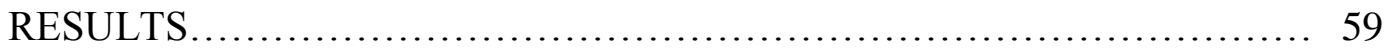

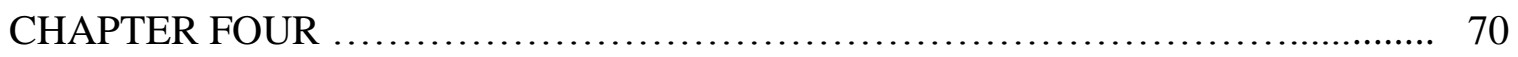

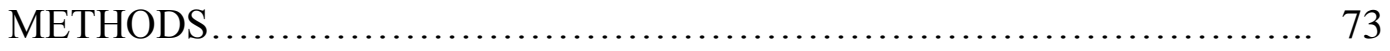

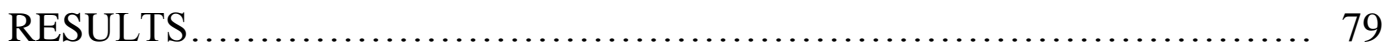

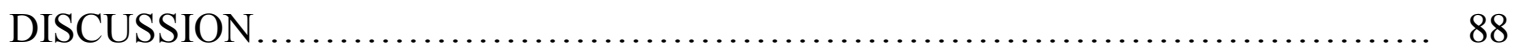

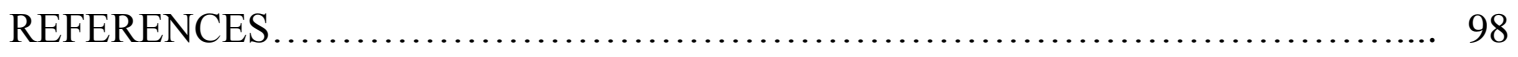

APPENDICES.................................................................... 106

CURRICULUM VITA........................................................... 111 


\section{LIST OF TABLES}

TABLE

PAGE

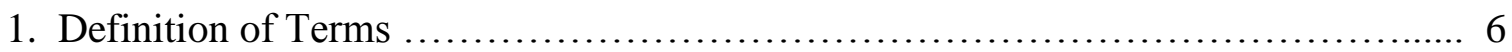

2. AAP Recommended Developmental Screening Schedule $\ldots \ldots \ldots \ldots \ldots \ldots \ldots \ldots \ldots . \ldots$

3. AAP Recommended Developmental Screening Tools ......................... 11

4. Kirkpatrick's Four Levels for Evaluating Educational Interventions ................ 24

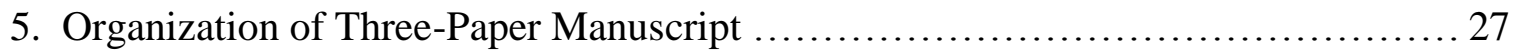

6. AAP Recommended Developmental Screening Schedule ........................ 38

7. Kirkpatrick's Four Levels for Evaluating Educational Interventions ............... 41

8. Kirkpatrick's Four Levels for Evaluating Educational Interventions ............... 51

9. Brief Outline of the PEDS Educational Intervention ............................. 58

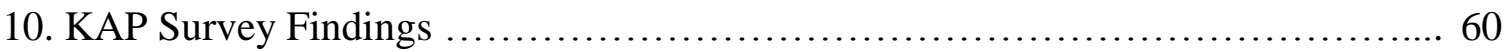

11. KAP Survey Findings by Group Educational Level........................ 61

12. Number and Type of Scoring Errors.................................... 64

13. Number and Type of Scoring Errors by Education and Work Experience........ 66

14. Calculated Error Rates............................................. 67

15. Kirkpatrick's Four Levels for Evaluating Educational Interventions............ 73

16. Phases of Thematic Analysis....................................... 75 


\section{CHAPTER ONE \\ INTRODUCTION}

Developmental and behavioral health disorders are now the top five chronic pediatric conditions causing functional impairment (Halfon, Houtrow, Larson, \& Newacheck, 2012). In the United States, about one in six children ages 3-17 years has developmental disabilities of varying severity. According to the Centers for Disease Control and Prevention (CDC), developmental disabilities include impairments in physical, learning, language or behavior areas that begin in childhood, impact day-to-day functioning, and typically last throughout a person's lifetime (Centers for Disease Control and Prevention, 2018). It is known that developmental disabilities are often not identified until after school entrance, increasing the likelihood that the disabilities will persist throughout the school-age years and into adulthood, raising the risk of onset of secondary mental health problems often born from school failure (Rice et al., 2014). Children whose developmental concerns remain unidentified face an increased risk for compromised health, safety, and developmental delays (Rice et al., 2014). It is believed that developmental disabilities are caused by a complex mix of factors including genetics, parental behaviors (such as smoking and drinking during pregnancy), complications during birth, infections during pregnancy or early life, and exposure to environmental toxins, such as lead (Centers for Disease Control and Prevention, 2015). While a combination of hereditary, environmental, and socio-demographic risk factors may compromise a young child's development, early intervention for mental, behavioral, and 
developmental delays, can mitigate their impact. There is considerable evidence demonstrating that early intervention services produce positive effects regarding developmental outcomes (Bradley, Burchinal, \& Casey, 2001; Lipkin \& Schertz, 2008; Sameroff, 2000). Increasing the use of early intervention services can result in substantial reductions in the burden of illness, death, and disability, and lower treatment costs (Yeung et al., 2014). A system that promotes the identification of at-risk children can assist in closing the widening gap between children who lack services for developmental concerns and those who access services in a timely manner.

\section{The Importance of Early Identification}

National data suggests that only $2-3 \%$ of children identified with developmental disabilities currently receive early intervention services, despite substantial evidence demonstrating that early intervention services produce positive effects regarding developmental outcomes (Bitsko et al., 2016; Centers for Disease Control and Prevention, 2018; Rice et al., 2014). Recently, there has been an increase in cost for individuals with developmental disabilities (Zablotsky, Black, \& Blumberg, 2017). This cost increase is a result of the need for more comprehensive interventions because developmental delays were left untreated, resulting in compounded adverse outcomes. Increasing the use of early intervention services can result in marked reductions in treatment costs (Yeung et al., 2014; Zablotsky et al., 2017). Developmental disabilities have important impacts on society in terms of direct and indirect costs. Considerable resources are expended for the educational, medical, and community support of individuals with developmental delays and conditions (Boyle et al., 2011; Halfon et al., 2012). Affected children have significantly higher rates of healthcare use compared to 
children without such conditions (Boyle et al., 2011; Halfon et al., 2012). The economic costs to society associated with developmental conditions, including expenditures for additional medical care, and indirect costs related to lost productivity, were estimated to be an average of greater than $\$ 1,000,000$ over the patient's lifetime (Boyle et al., 2011).

Prevalence rates for Kentuckians with a mental, behavioral, or developmental disorder in early childhood surpass the national average, and are the highest in the nation, at $21.5 \%$ (Bitsko et al., 2016). Greater than $90 \%$ of pediatricians practicing in primary care settings in Kentucky report that they see at least one patient a month with 1 of 10 specific behavioral/mental health diagnoses (Davis et al., 2012). According to the Early Childhood Branch of Kentucky's Cabinet for Health and Family Services, approximately $21 \%$ of all children receiving preventative health services are in need of further evaluation and treatment of a condition or problem that, when detected early, is less costly than if allowed to worsen. It has been estimated that there is a $\$ 7$ return for every dollar invested in early intervention, with benefits to society including more efficient use of school services and less use of criminal justice and other public systems (Kentucky Cabinet for Health and Family Services, 2016).

Several national organizations and programs have developed guidelines and quality care indicators for early screening and identification of developmental concerns or delays in young children (Rice et al., 2014). The Centers for Disease Control and Prevention (CDC), The American Academy of Pediatrics (AAP), and Healthy People 2020 have all endorsed measures for periodic developmental screening of children as indicators of effective and timely population health services (American Academy of Pediatrics, 2006; Centers for Disease Control and Prevention, 2018; Healthy People 
2020). Currently, programs are underway that may increase the use of developmental screening in healthcare settings (Guevara et al., 2013). These efforts include initiatives to improve awareness of typical child developmental milestones and indicators of developmental concern, and to encourage parents, healthcare providers, and early childhood educators and interventionists to engage in developmental monitoring (Daniel, Prue, Taylor, Thomas, \& Scales, 2009). Healthcare professionals must be prepared to use valid and reliable screening tools and develop systems of care that screen children early, linking these children to services (Guevara et al., 2013). Determining ways in which routine developmental screening can be implemented effectively and efficiently is critical to address the number of children with developmental disabilities who do not access early intervention services.

\section{Context}

General Pediatric Practice and Young Children

In the United States, almost 95\% of children between birth and three years of age report a regular source of healthcare (Centers for Disease Control and Prevention, 2018). The majority of clinical preventative services for infants and children are provided through primary care clinics (Yeung et al., 2014). When general pediatricians collaborate with families and make referrals to early intervention services, they are able to provide a medical home for young children with, or at risk for, developmental disabilities (Cooley \& McAllister, 2004). Within the medical home approach, high quality and cost-effective health care can be provided by the pediatrician who works in a partnership with the family. This care is continuous, coordinated, and comprehensive. Since primary care clinics have frequent contact with infants and young children during critical times in their 
early development, clinicians at these sites are well suited for the detection of developmental delays in children. This frequent longitudinal contact, unique to primary care, provides pediatricians and clinical staff with important opportunities to conduct screening to detect developmental delays in young children and to initiate early intervention.

\section{Defining Developmental Monitoring}

Developmental surveillance is a flexible, continuous process used by professionals who conduct skillful observations of young children during the provision of primary care (American Academy of Pediatrics, 2006). Screening is a brief assessment procedure used to identify children who should receive a more comprehensive assessment or intensive diagnosis (American Academy of Pediatrics, 2006). Specifically, screening complements the surveillance process by detecting delays or disabilities through the periodic use of standardized tools for all children (American Academy of Pediatrics, 2006). Within both processes, healthcare providers such as general pediatricians and nursing staff can assist with early identification of children with a variety of concerns, including cognition, communication, motor functions, socialemotional capacity, self-help or adaptive, sensory, and problem-solving skills (Sheldrick \& Perrin, 2009). Developmental surveillance and screening during well-child visits assists in helping healthcare professionals to offer preventive guidance to families of children with developmental difficulties (American Academy of Pediatrics, 2006). Table 1 provides a summary of terms used when discussing the identification of developmental delays. The level of scrutiny increases from least (developmental surveillance) to greatest (developmental assessment/evaluation). 


\section{Table 1. Definition of Terms}

\begin{tabular}{ll}
\hline Term & Definition \\
\hline Developmental surveillance (monitoring) & $\begin{array}{l}\text { Use of information from multiple sources } \\
\text { (parent concerns or questions, asking about } \\
\text { developmental milestones, informal } \\
\text { observation of the child, and physical } \\
\text { examination) to monitor a child's } \\
\text { development over time }\end{array}$ \\
\hline Developmental screening & $\begin{array}{l}\text { Systematic use of a validated screening } \\
\text { tool to identify children likely to have a } \\
\text { developmental delay, with all children in a } \\
\text { practice or population, regardless of risk }\end{array}$ \\
\hline Secondary/selective developmental & $\begin{array}{l}\text { Use of a validated screening tool with a } \\
\text { subset of children identified as having an } \\
\text { increased risk for developmental delays. } \\
\text { These children might be identified through } \\
\text { developmental surveillance }\end{array}$ \\
\hline Developmental assessment/evaluation & $\begin{array}{l}\text { Formal testing of a child's developmental } \\
\text { skills using a standardized assessment tool, } \\
\text { and/or, evaluation by a specialist in the } \\
\text { area of child development, to determine } \\
\text { the specific nature of a child's } \\
\text { developmental difficulties and diagnosis }\end{array}$ \\
& \\
&
\end{tabular}

(Adapted from American Academy of Pediatrics, 2006)

\section{Early Detection Policy}

Although nearly all young children have regular primary care visits during which developmental problems could be identified, it is well-documented that many pediatricians are failing to identify children in need of early intervention services in a timely manner (Halfon et al., 2004; Jimenez et al., 2014; Rice et al., 2014; Sices et al., 2008; Sices, Feudtner, McLaughlin, Drotar, \& Williams, 2004; Zuckerman, Stevens, Inkelas, \& Halfon, 2004). In 2001, the American Academy of Pediatrics (AAP) 
announced a new policy statement strongly recommending that all pediatricians begin incorporating the use of standardized, validated developmental screening in to their routine clinical practices. These guidelines were written to assist general pediatricians and other pediatric healthcare providers with screening for developmental disabilities and intervening with identified children and their families within the framework of a medical home. Despite the policy implementation in 2001, routine use of developmental screening has been minimal, and several barriers to implementation have been reported. Cited barriers included: cost, time, lack of knowledge of standardized developmental screening tools, and lack of manpower to complete periodic screening (Halfon et al., 2004; Sand et al., 2005; Sices et al., 2004). As a result, the guidelines were revised by the AAP in 2006. The 2006 revisions represent the current recommended practice guidelines, and include administration of a standardized developmental screening tool at the 9-, 18-, and 24- or 30-month well-child visits, as well as any time a family or clinician has concerns. A total of nine different standardized screening tools were recommended by the AAP (American Academy of Pediatrics, 2006). A summary of the AAP recommendations on developmental surveillance, screening, and referral at well-child checks is presented in Table 2 . 


\section{Table 2. AAP Recommended Developmental Screening Schedule}

1. At each visit through the age of 5 years:

- Developmental surveillance

- If concern during surveillance, complete general developmental screening

2. At 9-, 18-, and 24- or 30-months visits:

- General developmental screening with a validated screening tool (all children)

At 18- and 24- or 30-months visits: Autism-specific screening

3. If positive screen result (9-, 18, and 24- or 30-months visits):

- Refer child for developmental and medical evaluation

- Refer child to Early Intervention services ( $<3$ years old)

- Refer child to early childhood services $(\geq 3$ years old)

The use of quality screening tools doubles identification rates of children with developmental problems and significantly increases enrollment in needed interventions (Glascoe \& Squires, 2013).

\section{AAP Recommended Screening Tools}

There are a great number of developmental screening tools that have been published and utilized over the past few decades. To date, there has never been a screening tool recognized as a "gold standard" that has been universally accepted and appropriate for all ages and populations (American Academy of Pediatrics, 2006; Aylward, 2009). Fortunately, however, there have been several instruments developed that do meet the AAP guidelines for selecting quality instruments (American Academy of Pediatrics, 2006). Screening tools generally fall into 1 of 2 categories: those that require direct elicitation and observation of a child; and those that rely solely on parental or 
caregiver report (Hamilton, 2006). Screening instruments can be further divided into those tools that assess multiple developmental domains, versus ones that are either condition-specific, aimed at identifying a specific developmental condition (e.g., autism spectrum disorder), or domain-specific, aimed at screening a particular area (e.g., speech and language) (American Academy of Pediatrics, 2006). Direct measures of general development tend to be the most commonly recognized and utilized screening tests, and recommendations have focused on these types of tools, although the most recent AAP statement endorses the use of an autism-specific screen at the 18-month and 24-month visits, even in the absence of a suspicion of autism (American Academy of Pediatrics, 2006). Other than the autism-specific screen, condition-specific screening tools are not typically recommended for general screening in primary care. In the area of speech and language development, the U.S. Preventative Services Task Force recently concluded that there was insufficient evidence to recommend the use of specific screening to detect speech and language delays in young children (Nelson, Nygren, Walker, \& Panoscha, 2006). In general, direct screening measures tend to require formal training in administration, scoring, and interpretation. Further, although not a characteristic of all direct screening tests, many tend to have longer administration times when compared to indirect administration instruments (Hamilton, 2006).

\section{Criteria for Selection}

Stringent criteria exist for screening tools to detect developmental concerns. Researchers and developers have continued to improve the quality and efficiency of developmental screening tests, with many now available that can be completed in approximately 15 minutes or less. Many tools are considered efficient, especially those 
that have adequate sensitivity, specificity, validity, and reliability, and have been standardized over diverse populations. A 2003 study notes that "sensitivity" refers to the proportion of children with a disorder who are identified by the screening tool, and "specificity" includes the proportion of children without the disorder who the screening tool identifies as exhibiting normal development (Charman et al., 2003). Sensitivity should be high on developmental screening tools so that the screen misses few cases of the disability concerns, while specificity also must be high to prevent the identification of false positives (Charman et al., 2003). High reliability of a screening tool demonstrates that the tool is consistently measuring a construct or domain, and high validity of a screening tool demonstrates that the tool is measuring what it is supposed to measure the developmental patterns of young children (Charman et al., 2003). Screening tools with these attributes are recommended for use by general pediatricians when determining a child's level of skill and development (American Academy of Pediatrics, 2006). Table 3 provides a detailed list of the general developmental screening instruments recommended by the AAP. 
Table 3. AAP Recommended Developmental Screening Tools

\begin{tabular}{|c|c|c|c|c|c|}
\hline & Description & Age Range & No. of Items & $\begin{array}{l}\text { Administration } \\
\text { Time }\end{array}$ & Psychometric Properties \\
\hline $\begin{array}{l}\text { Ages \& Stages } \\
\text { Questionnaire (ASQ) }\end{array}$ & $\begin{array}{l}\text { Parent-completed; } \\
\text { series of } 19 \text { age- } \\
\text { specific } \\
\text { questionnaires } \\
\text { screening five } \\
\text { developmental } \\
\text { domains; pass/fail } \\
\text { score with cutoff } \\
\text { indicating possible } \\
\text { need for further } \\
\text { assessment }\end{array}$ & 4-60 months & 30 & $10-15$ minutes & $\begin{array}{l}\text { Normed on } 2008 \text { children from } \\
\text { diverse ethnic backgrounds; } \\
\text { Sensitivity: 0.70-0.90 (moderate to } \\
\text { high) } \\
\text { Specificity: } 0.76-0.91 \text { (moderate to } \\
\text { high) }\end{array}$ \\
\hline $\begin{array}{l}\text { Batelle Developmental } \\
\text { Inventory Screening } \\
\text { Tool, } 2^{\text {nd }} \text { ed (BDI-ST) }\end{array}$ & $\begin{array}{l}\text { Direct administration; } \\
\text { assess five } \\
\text { developmental } \\
\text { domains; pass/fail } \\
\text { score and age- } \\
\text { equivalent with cutoff } \\
\text { indicating need for } \\
\text { referral }\end{array}$ & $\begin{array}{l}\text { Birth-95 } \\
\text { months }\end{array}$ & 100 & $\begin{array}{l}10-15 \text { min } \\
(<3 \text { years old }) \\
20-30 \text { min } \\
(>3 \text { years old })\end{array}$ & $\begin{array}{l}\text { Normed on } 2500 \text { children with } \\
\text { demographic information matched to } \\
2000 \text { US Census data; Sensitivity: } \\
0.72-0.93 \text { (moderate to high) } \\
\text { Specificity: } 0.79-0.88 \text { (moderate) }\end{array}$ \\
\hline $\begin{array}{l}\text { Bayley Infant } \\
\text { Neurodevelopmental } \\
\text { Screen (BINS) }\end{array}$ & $\begin{array}{l}\text { Direct administration; } \\
\text { series of six item sets } \\
\text { screening basic } \\
\text { neurologic functions; } \\
\text { results in risk category } \\
\text { (low, moderate, high } \\
\text { risk) }\end{array}$ & 3-24 months & $11-13$ & $10 \mathrm{~min}$ & $\begin{array}{l}\text { Normed on } \sim 1700 \text { children and } \\
\text { stratified on age to match the } 2000 \text { US } \\
\text { Census data; Sensitivity: } 0.75-0.86 \\
\text { (moderate) } \\
\text { Specificity: } 0.75-0.86 \text { (moderate) }\end{array}$ \\
\hline Brigance Screens-II & $\begin{array}{l}\text { Direct administration } \\
\text { (or parent report if } \\
\text { under } 24 \text { months of } \\
\text { age); series of nine } \\
\text { forms screening } 7\end{array}$ & 0-90 months & $8-10$ & $10-15$ min & $\begin{array}{l}\text { Normed on } 1156 \text { children from } \\
\text { clinical sites in } 21 \text { states; Sensitivity: } \\
0.70-0.80 \text { (moderate) Specificity: } \\
0.70-0.80 \text { (moderate) }\end{array}$ \\
\hline
\end{tabular}




\begin{tabular}{|c|c|c|c|c|c|}
\hline & developmental areas & & & & \\
\hline $\begin{array}{l}\text { Child Development } \\
\text { Inventory (CDI) }\end{array}$ & $\begin{array}{l}\text { Parent-completed; } \\
\text { measures five } \\
\text { developmental } \\
\text { domains; results in } \\
\text { developmental } \\
\text { quotients and age } \\
\text { equivalents; indication } \\
\text { for more in-depth } \\
\text { evaluation }\end{array}$ & $\begin{array}{l}18 \text { months- } 6 \\
\text { years }\end{array}$ & 300 & $30-50 \mathrm{~min}$ & $\begin{array}{l}\text { Normed on } 568 \text { children from a white, } \\
\text { working class community; Sensitivity: } \\
0.80-1.0 \text { (moderate to high) } \\
\text { Specificity: } 0.94-0.96 \text { (high) }\end{array}$ \\
\hline $\begin{array}{l}\text { Child Development } \\
\text { Review-Parent } \\
\text { Questionnaire (CDR- } \\
\text { PQ) }\end{array}$ & $\begin{array}{l}\text { Parent- completed } \\
\text { questionnaire; } \\
\text { professional- } \\
\text { completed child } \\
\text { development chart } \\
\text { assessing four } \\
\text { developmental } \\
\text { domains; results } \\
\text { provide observation } \\
\text { guide or parent } \\
\text { interview guide }\end{array}$ & $\begin{array}{l}18 \text { months- } 5 \\
\text { years }\end{array}$ & $\begin{array}{l}6 \text { open-ended } \\
\text { items and a 26- } \\
\text { item checklist } \\
\text { to be completed } \\
\text { by parent, } \\
\text { followed by } 99 \\
\text { items assessing } \\
\text { developmental } \\
\text { domains }\end{array}$ & $10-20 \mathrm{~min}$ & $\begin{array}{l}\text { Standardized with } 220 \text { children aged } \\
\text { 3-4 years from a white, working class } \\
\text { community; Sensitivity: } 0.68 \text { (low) } \\
\text { Specificity: } 0.88 \text { (moderate) }\end{array}$ \\
\hline $\begin{array}{l}\text { Denver-II } \\
\text { Developmental } \\
\text { Screening Test }\end{array}$ & $\begin{array}{l}\text { Direct administration; } \\
\text { screens four } \\
\text { developmental } \\
\text { domains; results in } \\
\text { risk category (normal, } \\
\text { questionable, } \\
\text { abnormal) }\end{array}$ & $0-6$ years & 125 & $10-20 \mathrm{~min}$ & $\begin{array}{l}\text { Normed on } 2096 \text { children in } \\
\text { Colorado; diversified in terms of age, } \\
\text { place of residence, ethnicity, maternal } \\
\text { education; Sensitivity: } 0.56-0.83 \text { (low } \\
\text { to moderate) Specificity: } \\
0.43-0.80 \text { (low to moderate) }\end{array}$ \\
\hline $\begin{array}{l}\text { Infant Development } \\
\text { Inventory }\end{array}$ & $\begin{array}{l}\text { Parent-completed; } \\
\text { questionnaire } \\
\text { measuring four } \\
\text { developmental } \\
\text { domains }\end{array}$ & $0-18$ months & $\begin{array}{l}4 \text { open-ended } \\
\text { questions } \\
\text { followed by } 87 \\
\text { items crossing } \\
\text { developmental } \\
\text { domains }\end{array}$ & 5-10 minutes & $\begin{array}{l}\text { Studied in } 86 \text { high-risk } 8 \text {-month-olds } \\
\text { and compared with Bayley scales; } \\
\text { Sensitivity: } 0.85 \text { (moderate) } \\
\text { Specificity: } 0.77 \text { (moderate) }\end{array}$ \\
\hline
\end{tabular}




\begin{tabular}{|l|l|l|l|l|l|}
\hline $\begin{array}{l}\text { Parents' Evaluation of } \\
\text { Developmental Status } \\
\text { (PEDS) }\end{array}$ & $\begin{array}{l}\text { Parent-completed; } \\
\text { screens for } \\
\text { developmental and } \\
\text { behavioral problems } \\
\text { needing further } \\
\text { evaluation; single } \\
\text { response form used } \\
\text { for all ages; may be } \\
\text { used as a surveillance } \\
\text { tool }\end{array}$ & $0-8$ years & 10 & $2-10$ min & $\begin{array}{l}\text { Standardized with } 771 \text { children from } \\
\text { diverse socioeconomic backgrounds; }\end{array}$ \\
Sensitivity: 0.74-0.79 (moderate) \\
Specificity: 0.70-0.80 (moderate)
\end{tabular}

(American Academy of Pediatrics, 2006) 
As can be seen from the table above, a number of the recommended standardized instruments have proven to meet acceptable practice standards for sensitivity and specificity in detecting developmental delays (King et al., 2010; Pinto-Martin, Dunkle, Earls, Fliedner, \& Landes, 2005; Rice et al., 2014).

Two developmental screening tools are particularly widely used by pediatricians: the Parents' Evaluation of Developmental Status (PEDS) and the Ages and Stages Questionnaire (ASQ) (Hornman, Kerstjens, de Winter, Bos, \& Reijneveld, 2013; Radecki, Sand-Loud, O'Connor, Sharp, \& Olson, 2011). Both instruments have published validation studies and have been validated in large, diverse standardization samples (Drotar, Stancin, Dworkin, Sices, \& Wood, 2008). In these studies, the PEDS had moderate sensitivity (74\%) but low specificity (64\%), while the ASQ had moderate sensitivity and moderate specificity (78\% and 75\%, respectively) (Limbos \& Joyce, 2011).

Both the ASQ and PEDS are parent-report measures to screen for general developmental delay (Drotar et al., 2008). Popularity of these tools is due to several favorable qualities, including completion by parents, the ease of administration and interpretation, and low cost, making them affordable for frequent use (Limbos \& Joyce, 2011; Mackrides \& Ryherd, 2011). Additionally, because these tools are parentcompleted, clinicians do not need to administer the instrument during the patient visit, potentially saving time, which is often reported as a barrier to using such instruments (Rydz et al., 2006). There has been a recent increase in the use of the PEDS in pediatric primary care practices compared to other AAP-recommended developmental screening tools owing to its ease of administration and interpretation, and low cost (Hornman et al., 
2013; Limbos \& Joyce, 2011; Mackrides \& Ryherd, 2011; Radecki et al., 2011; World Health Organization, 2008). The PEDS is designed to elicit and address parents' concerns about their child's learning, development, health and behavior, and is designed for age birth to 8. Parents are asked to answer 10 (yes/no/a little) questions on the PEDS Response Form.

\section{Developmental Screening Practices of General Pediatricians}

\section{Implementation Practices}

The use of validated developmental screening tools is supported by American Academy of Pediatrics (AAP) guidelines, but these instruments are used variably by general physicians in pediatric practice. Although practice guidelines from the AAP recommend the use of developmental screening tools in primary care, most physicians do not appear to use these tools systematically, if at all. Recent research indicates that most physicians report using developmental milestone lists or informal checklists as part of an overall strategy of developmental surveillance (Sand et al., 2005; Sices, Feudtner, McLaughlin, Drotar, \& Williams, 2003). A much smaller number of physicians report using a validated developmental screening instrument (Sices et al., 2003, 2004), and most use the tools selectively, rather than regularly, and only with suspected or at-risk patients (Silverstein et al., 2006). Furthermore, many parents report that no developmental screening occurred during their well-child visits (Rice et al., 2014).

Despite recommendations by the AAP in 2006 for increased developmental screening, screening rates remain less than optimal. Radecki (2009) compared pediatricians' use of standardized screening tools from 2002 to 2009. In 2002, less than 
$25 \%$ of pediatricians reported always or almost always using a screening tool to identify developmental delays in young children (Radecki et al., 2011). This percentage increased to greater than $47 \%$ of pediatricians implementing a developmental screening tool in 2009 (Radecki et al., 2011). Although the number of pediatricians who reported using a formal screening tool more than doubled between 2002 and 2009, the percentage remains less than half of respondents providing care to patients younger than 36 months of age (Radecki et al., 2011).

Schonwald et al., (2009) examined the feasibility and effectiveness of implementation of a validated developmental screening tool in two urban pediatric practices. This study offered developmental screening to all patients attending well-child visits between the ages of 6 months and 5 years (Schonwald, Huntington, Chan, Risko, \& Bridgemohan, 2009). Retrospective chart review of the two- and three-year-olds attending well-child visits at the clinic was completed to determine identification rates and referral rates for developmental concerns. Findings indicated that screening rates increased, but only to $61.6 \%$ of eligible children (Schonwald et al., 2009). Morelli et al., (2014) completed a similar project. In this study, clinicians at four urban pediatric practices were charged with implementing developmental screening using a specified tool at the 9-, 18-, 24-, and 30-month visits (Morelli et al., 2014). Participants included 1397 children less than 36 months of age, and $84 \%$ of participants were screened during at least one well-child visit. While it seems that a large number of eligible children were screened, some of these children were screened on only one occasion, rather than routinely as recommended by the AAP (Morelli et al., 2014). 
Nearly a decade after the AAP mandated developmental screening at well-child visits, many practices have still not adopted this preventative measure. In the most recent study to date examining the use of standardized developmental screening by general pediatricians, Keil et al. (2014) surveyed 157 primary care pediatricians in Wisconsin to assess routine use of developmental and autism-specific tools (Keil, Breunig, Fleischfresser, \& Oftedahl, 2014). Results from this study found that a mere 55\% of clinicians reported use of validated developmental and autism-specific screening tools within well-child care (Keil et al., 2014).

\section{Barriers to Implementation}

Barriers to the early identification and referral of children with developmental delays exist within the general pediatrician's daily routine and within the nature of assessing a child's developmental status. Sices et al. (2004) conducted a mail survey with family physicians and general pediatricians to determine their practices when identifying children with developmental delays during preventative care visits. The findings of this study demonstrated that most physicians elicited the presence of developmental problems by using lists of developmental milestones and/or verbal prompting of parental concern. Validated instruments were not used, and, in fact, less than $15 \%$ of the physicians in this study used parent-completed questionnaires which have been shown to be reliable and timesaving (Sices et al., 2004). Finally, physicians reported themselves as the primary individuals responsible for developmental surveillance and screening, which indicated that the use of other office personnel for this task did not occur within the pediatrician's office (Sices et al., 2004). 
Although general pediatricians may consider themselves more competent at identifying any developmental concerns when compared to other practitioners, a 2000 AAP survey found that two-thirds of pediatricians did not feel adequately trained to conduct developmental assessments (Halfon et al., 2004). In fact, pediatricians reported spending most of their time with parents discussing typical concerns such as immunizations, nutrition, and sleep issues. Specifically, the Promoting Healthy Development Survey (PHDS) was created to assist providers, consumers, purchasers, and policy makers in assessing the degree to which health plans and practitioners provide recommended developmental services for children up to four years of age. Results from the PHDS, which examined the quality of services within a large population $(n=3542)$ of Medicaid-enrolled children in Washington State, showed that approximately 50\% of the parents reported having one or more insufficiently answered behavioral or developmental concerns after visiting their child's health provider (Halfon et al., 2004). Additionally, parental responses showed that $42 \%$ of the children within this population were at a high risk for developmental and/or behavioral delays, yet had not been identified as needing services (Halfon et al., 2004).

Paying for standardized screening instruments also poses a concern for pediatricians; therefore, financial incentives aligned with the goals for improving preventive services were a reported need in a 2014 study (Rice et al., 2014). Another reported barrier related to cost involved the use of billing codes for the reimbursement of preventative care visits. A 2004 study reported significant discrepancies in the billing practices of physicians, and called for the billing and payment for developmental screening services to be standardized (Zuckerman et al., 2004). According to the AAP, 
the correct coding of services was necessary for increased efficiency and timely referral of children with developmental concerns (Aylward, 2009).

A final commonly cited problem in implementation of developmental screening by pediatricians in general practice is two-fold. A handful of studies have documented that physicians believed that due to high patient caseload, limited time was available to spend with each patient and family. Therefore, implementation of a standardized screening tool was not feasible. In addition, physicians reported lack of support staff to assist with the administration and scoring of the screen to alleviate the perceived time crunch (Jimenez et al., 2014; Sices et al., 2008).

\section{The Expanding Roles of Medical Support Personnel}

The work roles of medical support personnel in healthcare settings are expanding. With developments in medical technology, a push toward evidence-based, patientcentered care, and the need to increase access to primary care, a transformation in healthcare delivery is occurring nationally (Bodenheimer, Willard-Grace, \& Ghorob, 2014). To comply with these changes, some primary care practices are expanding the roles of registered nurses and behavioral health professionals. The clinical workforce in many practices, however, consists of minimally trained, unlicensed medical support staff (Bodenheimer et al., 2014). Despite their lack of formal training, medical support personnel are being tasked with responsibilities such as: tracking lab reports (Naughton, Adelman, Bricker, Miller-Day, \& Gabbay, 2013); administering vaccines (Ladden et al., 2013); serving as health coaches to improve lifestyle behaviors (Djuric et al., 2017); clinical scribing (Bodenheimer et al., 2014); and screening patients for risky behaviors (smoking, drinking, low physical activity, and unhealthy diet) (Ferrer, Mody-Bailey, 
Jaen, Gott, \& Araujo, 2009). Outcomes in studies that have focused on or included the role expansion of medical support personnel have varied, and there is currently a limited understanding as to why there was success in some studies and not in others (Ferrante et al., 2018). Having a clearer understanding of how to best equip medical support personnel for their changing roles in healthcare is critical to patient care outcomes, and can provide insights into an understudied area of the transformation that is occurring in primary care practice (Bodenheimer et al., 2014; Ferrante et al., 2018).

\section{Defining the Problem}

Despite the AAP's 2006 mandate, many general pediatricians' offices continue to struggle with implementing the recommendation of routine, standardized developmental screening during well-child visits (King et al., 2010). Several factors have reportedly made the process of early identification and timely referral of young children with developmental delays difficult, including: unfamiliarity with the screening tools used to detect developmental delays; insufficient time to administer standardized screening tools during well-child appointments; a lack of non-physician staff to assist with developmental screening; cost; and a lack of confidence in the ability to screen (Chapman, Marks, \& Dower, 2015; Halfon et al., 2012; Jimenez et al., 2014; Rice et al., 2014; Sices et al., 2008; Sices et al., 2004). Support for this problem statement exists because of the nonfulfillment of the APA's clinical practice guidelines by general pediatric practitioners. Furthermore, the lack of reported tailored educational interventions to teach and train up-and-coming physicians and medical support personnel on the implementation and scoring of AAP recommended standardized developmental screening tools substantiates the problem. This public health study is both timely and 
essential. This study seeks to provide evidence to support a solution to an identified problem, and seeks to add to the paucity of published studies identifying successful educational interventions facilitating the use of standardized developmental screening in general pediatric practice.

\section{Theoretical Framework}

\section{Diffusion of Innovations Model}

Implementation of effective interventions is a significant challenge for public health and medicine (Painter, Borba, Hynes, Mays, \& Glanz, 2008). The Diffusion of Innovations model has been used over several decades to understand the steps and processes required to achieve wide-spread dissemination and diffusion, and implementation of health innovations (Glanz, 2008). While some innovations diffuse rapidly, others are weakly or never adopted, or are implemented and then abandoned. Often, when considering the adoption of new clinical initiatives and evidence-based medicine, uptake is slow. Glanz (2008) notes that, “...it has been recognized...that the implementation of clinical guidelines depends both on organizational and system changes and on individual clinicians' behaviors" (p.315). Although the AAP issued a statement recommending the screening of young children at designated ages, provided an algorithm for implementation, and endorsed a list of validated screening tools, diffusion of this practice among pediatricians and pediatric practices as a whole has ultimately been poor (American Academy of Pediatrics, 2006). The present study seeks to determine a path to adoption of routine developmental screening in pediatric primary care. The current study seeks to influence the individual behaviors of medical support personnel by providing an educational intervention to provide knowledge of developmental screening and stimulate 
screening by this group in practice. This environmental support - the educational training - would encourage developmental screening to take place, and have an impact on the ability of medical support personnel to successfully complete developmental screening on clinic patients by creating an environment that inspired this behavior.

It is clear that barriers and facilitators exist at multiple levels of the implementation process and that the process requires adequate preparation, communication, practice, and follow through (American Academy of Pediatrics, 2006). Factors that either enable or prevent implementation of a standardized developmental screening tool to identify developmental delays in children have been documented at the organizational level (relative advantage, complexity, cost effectiveness, feasibility); the practitioner level (attitudes, motivations, confidence level, readiness toward, learning style); and the policy level (changes in policy, changes in the roles and functions of personnel, training readiness and efforts) (Wisdom, Chor, Hoagwood, \& Horwitz, 2014).

Because the field of public health seeks to implement evidenced-based interventions that have been rigorously evaluated and found to be both effective and efficacious, determining the 'best' intervention to address an identified concern is of the utmost importance. Bowen et al., (2009) define intervention as, "any program, service, policy, or product that is intended to ultimately influence or change people's social, environmental, and organizational conditions as well as their choices, attitudes, beliefs, and behaviors" (p.452-3). Both early conceptual models of health education and more modern versions of health promotion indicate that interventions should focus on changeable behaviors and objectives, be relevant to target populations, be based on 
empirical evidence linking behavior to health, and have the potential to meet the intervention's goals (Bowen et al., 2009).

\section{Kirkpatrick's Four Level Evaluation Model}

Evaluation of models of educational interventions for medical support personnel is necessary so that trainings can be developed and implemented for the benefit of patients. Kirkpatrick's four level evaluation model is a widely used methodology for assessing educational interventions (Kirkpatrick, 1976). The four levels are: (1) Reaction: the acceptability of the training to the participants; (2) Learning: the knowledge, skills, or attitudes acquired by the participants; (3) Behavior: the application of learning in practice; and (4) Results: the effect on patients. Level one includes assessment of training participants' reaction to the training program. In practice, measures at this level are most commonly directed at assessing trainees' affective responses to the quality (i.e. satisfaction with the instructor) or the relevance (i.e. workrelated utility) of training (Kirkpatrick, 1976). Learning measures, level two, are quantifiable indicators of the learning that has taken place during the course of the training (Kirkpatrick, 1976). Level three, behavior outcomes, address either the extent to which knowledge and skills gained in training are applied on the job or results in increased job-related performance (Kirkpatrick, 1976). Lastly, level four outcomes are intended to provide some measure of the impact that training had on broader organizational goals and objectives (i.e. improved clinical outcomes; improved patient experience; enhanced efficiency; profitability) (Kirkpatrick, 1976). An evaluation methodology such as this should be used when considering the outcomes of educational interventions. In this study, Kirkpatrick's four-level evaluation model will be utilized to 
determine if each study reviewed complies with the four levels necessary for a successful educational intervention. Evaluation criteria are listed in Table 4.

Table 4. Kirkpatrick's Four Levels for Evaluating Educational Interventions

\begin{tabular}{|l|l|}
\hline Reaction & How training participants react to the intervention \\
\hline Learning & Effect on knowledge, skills, and attitudes \\
\hline Behavior & Extent to which behavior has changed \\
\hline Results & Final results - impact on patient care \\
\hline
\end{tabular}

The Knowledge, Attitude, and Behavioral Beliefs of Medical Support Personnel

Stakeholders play a role in implementing developmental screening guidelines. Stakeholders are defined as individuals and organizations that participate in a specific activity because they produce, consume, manage, regulate, or evaluate the activity (Omachonu, 2010). Stakeholders influence adoption of a proposed innovation and their support is necessary for successful implementation. In healthcare, key stakeholders include physicians, nurses, and other medical support personnel, patients, organizations such as healthcare systems and accrediting bodies, innovator companies, and regulatory agencies (Omachonu, 2010). To ensure success, a proposed innovation, such as implementing a developmental screening tool, should take into account each stakeholder's unique set of needs, wants, and expectations (Omachonu, 2010). Understanding the views of key decision makers can provide insight into the likelihood that policy changes needed for the intervention will occur. Also, consumer ideas, expectations, and concerns regarding the intervention can help predict the likelihood of successful implementation (Omachonu, 2010). In the present study, stakeholders 
influence adoption of a proposed innovation and their support is necessary for successful implementation (Titler, 2010).

Knowledge, Attitude, and Practice (KAP) questionnaires are essential in planning, implementing, and evaluating health practices. A well-designed KAP survey can produce data that are informative, insightful, and broadly useful in planning activities for medical support personnel in primary care practice (World Health Organization, 2008). KAP surveys can gather information about what respondents know about a particular health topic or condition, what they think about the health system's response to a health topic or condition, and they can identify needs, problems, and barriers in program delivery, as well as solutions for improving quality and accessibility of services (World Health Organization, 2008). For this study, a KAP survey is utilized as a pre-intervention measure of participant knowledge and beliefs about developmental screening, and as a post-intervention measure of participant knowledge and beliefs about developmental screening. Survey questions are presented in a Likert-style format, and questions remain the same on the pre- and post-study surveys.

\section{Purpose and Significance of Study}

A three-paper model is utilized to report the following purposes of the proposed study: 1) to assess the effect of an educational intervention to increase the knowledge of medical support personnel in pediatric primary care settings on the administration and scoring of a standardized developmental screening tool; 2) to determine if the medical support personnel are able to accurately score the tool in practice as accurately as the "gold standard"; and 3) to report the medical support personnel's experience of learning and applying a newly acquired skill in clinical practice. Development and 
implementation of the educational intervention in this study will be guided by Kirkpatrick's four-level evaluation model. The study purposes will address the following four levels: (1) Reaction: the acceptability of the training to the participants; (2) Learning: the knowledge, skills, or attitudes acquired by the participants; (3) Behavior: the application of learning in practice; and (4) Results: the effect on patients. This study ultimately seeks to discover not only if this intervention is successful in eliminating time as a barrier to pediatricians implementing this recommended practice, but also if the medical support staff increase their knowledge to accurately score the screening tool in order to assist general pediatricians in identifying children with or at risk for developmental disabilities in a timely manner. This study can add to the relatively small amount of literature regarding pediatricians' screening practices since the AAP's 2006 mandate by providing detailed and practical answers of how pediatric practices can overcome the perceived 'lack of time' barrier to implementation of a standardized screening tool at well-child visits. This information can be used to guide public health practitioners, in collaboration with other stakeholders, which have key roles in improving child health, understand the potential benefits of the recommended developmental screening. It can also be used to address the identified problem of underuse of screening tools in general pediatricians' offices, identify opportunities to apply effective strategies to improve use and foster accountability in developmental screening, and continue to promote this secondary level prevention procedure to reduce cost and improve overall health outcomes for this population. 


\section{Methodology}

In order to answer the study questions, both a synthesis of the literature and data collection will be completed. The study questions include: 1) To what extent did an educational intervention increase the knowledge of medical support personnel in pediatric primary care settings to administer and score a standardized developmental screening tool?; 2) Did differences occur between the scored developmental screening tool response forms of the medical support personnel and the expert scorer?; and 3) What was the experience of medical support personnel in learning and applying a newly acquired skill in clinical practice? An outline of the three-paper model is presented in Table 5.

Table 5. Organization of Three-Paper Manuscript

\section{Manuscript 1 Manuscript $2 \quad$ Manuscript 3}

\section{Study Question}

1. To what extent did an

X $\quad$ X

educational intervention

increase the knowledge of

medical support personnel

in pediatric primary care

settings to administer and

score a standardized

developmental screening

tool?

2. Did differences occur

$\mathbf{X}$

between the scored

developmental screening

tool response forms of the

medical support personnel

and the expert scorer?

3. What was the

$\mathbf{X}$

experience of medical

support personnel in

learning and applying a

newly acquired skill in 
clinical practice?

Manuscript One provides a discussion of the role educational interventions play in training healthcare personnel on novel skills in healthcare settings. Specifically, factors that should be considered for an appropriate educational intervention for medical support personnel in pediatric primary care are identified. A systematic, comprehensive approach is used to conduct a thorough review of the literature. Online public bibliographic databases including PubMed, EBSCO, ProQuest Direct, CINAHL, and Google Scholar will be searched to determine target articles. Concepts are derived from these publications, and include a combination of MESH terms and natural language terms. Search terms are broad and include the following: educational interventions; educational models; educational trainings; training; healthcare personnel; medical support staff; medical support personnel; medical assistants; primary care; pediatric primary care; medical home. Searches are conducted until all combinations of terms have been completed. Manuscripts outlining prior educational interventions will be given priority. Hand searches of reference lists of the most relevant articles are completed, as well as review of websites and grey literature, until saturation is reached. Articles published after the year 2008 are considered the most relevant. Older manuscripts are included when appropriate and only English-language studies are included. Identified papers are evaluated using Kirkpatrick's four-level evaluation model to determine if each complies with the four levels necessary for a successful educational intervention. The four levels are: (1) Reaction: the acceptability of the training to the participants; (2) Learning: the knowledge, skills, or attitudes acquired by the participants; (3) Behavior: the application of learning in practice; and (4) Results: the effect on patients. 
The focus of Manuscript Two is two-fold: 1) to determine the impact, before and after, of an educational intervention on medical support personnel's knowledge of administering and scoring a standardized developmental screening tool; and 2) to determine if differences occurred between the scored developmental screening tool response forms of the medical support personnel and the expert scorer. To measure the constructs in purpose one, a quantitative descriptive methodology with a one-group pretest, post-test interventional design will be utilized to determine if an educational intervention provided to medical support personnel will increase their knowledge to administer and score a standardized developmental screening. The independent variable is the educational intervention and the dependent variables are the medical support personnel's pre-test knowledge and post-test knowledge. The one-group pre-test, posttest interventional design with a cooling off period is depicted below:

$$
\mathrm{O}_{1} \quad \mathrm{X} \quad \text { (cooling off period) } \quad \mathrm{O}_{2}
$$

A within participants design is a weak design, but was decided for this study because all medical support personnel have to be trained (Creswell, 2009). A cooling off period of at least one month is included to reduce bias and to best determine knowledge retention (Bell et al., 2008). The following clinical question will be answered: To what extent did an educational intervention increase the knowledge of medical support personnel in pediatric primary care settings to administer and score a standardized developmental screening tool?

The second purpose of this manuscript is to determine the impact of the educational intervention on medical support personnel's ability to score the developmental screening tool as accurately as the "gold standard". This clinical question 
will be measured quantitatively with a descriptive methodology. The following question will be answered: Did differences occur between the scored developmental screening tool response forms of the medical support personnel and the expert scorer?

Manuscript Three seeks to report the experiences of medical support personnel's learning of a newly acquired skill, and the application of this skill in clinical practice. This clinical question will be measured qualitatively; three in-depth interviews with medical support personnel from each study location will be completed. The following question will be answered: What is the experience of medical support personnel in learning and applying a newly acquired skill in clinical practice?

\section{Human Subjects Protection}

This study is conducted in accordance with the Healthcare Information Portability and Accountability Act (HIPPA) regulations. The participants' privacy and confidentiality were maintained. Informed consent was obtained by the researcher, who has completed Protection of Human Subjects Training through the University of Louisville. The informed consent contained all relevant study material including: purpose, background, procedures, benefits, risks, the right to refuse or withdraw from the study, confidentiality, and the contact information of the researcher. The benefit-risk ratio was minimal to no risk and important benefits. The study protocol was submitted to and approved by the Institutional Review Board (IRB) at the University of Louisville (IRB\#: 19.0006).

\section{Summary and Organization of the Study}


Developmental delays are common in early childhood, and are predictive of later learning and behavioral difficulties. Early treatment of developmental delays leads to improved outcomes for children (Yeung et al., 2014). In order to benefit from early intervention, children with developmental delays must be identified and referred at a young age. General pediatricians have the opportunity to monitor young children's development during well-child visits between birth and age five, and are trained in child development and behavior; therefore they are ideally suited to identify developmental delays. Use of validated developmental screening tools is supported by American Academy of Pediatrics (AAP) guidelines, but these instruments are used variably and inconsistently by general physicians in pediatric practice (King et al., 2010). Children are currently not being identified in a timely manner, and are therefore not accessing early intervention services. Because of the expanding work roles of medical support personnel, it is worthwhile to determine if this group can administer and score a developmental screening tool after completing an educational intervention to assist general pediatric practices in using these tools in accordance with the AAP mandate, and enrolling more young children into early intervention services. Guided by Kirkpatrick's four-level evaluation model, the current study proposes: 1) to assess the effect of an educational intervention to increase the knowledge of medical support personnel in pediatric primary care settings on the administration and scoring of a standardized developmental screening tool; 2) to determine if the medical support personnel were able to score the selected tool in practice as accurately as the "gold standard"; and 3) to report the medical support personnel's experience of learning and applying a newly acquired skill in clinical practice. 
While Chapter One has provided an introduction to the study and has discussed the problem broadly, the following chapters (Chapters 2-4) will address components of the study in isolation. Manuscript One is presented in Chapter Two, and provides a synthesis of the literature surrounding the role educational interventions play in training healthcare personnel on novel skills in healthcare settings. Manuscript Two is presented in Chapter Three, and utilizes a one-group pre-test, post-test interventional design to determine the impact, before and after, of an educational intervention on medical support personnel's knowledge of administering and scoring a standardized developmental screening tool. This chapter also seeks to determine the impact of the educational intervention on medical support personnel's ability to score the developmental screening tool as accurately as the "gold standard". Manuscript Three is presented in Chapter Four, and qualitatively reports the experience of medical support personnel's learning of a newly acquired skill, and the application of this skill in clinical practice. Finally, Chapter Five provides a discussion of the major findings of all components of the study, study limitations, implications for future practice, and the overall contribution of this study's findings to the practice of health practitioners. Ultimately, the study findings seek to: facilitate understanding; contribute to the body of literature; allow for performance comparison; support future planning for pediatric practices and the changing landscape of care; guide the focus of stakeholders, policy makers, and influencers; improve patient outcomes; and reduce the financial burden of developmental delay. 


\section{CHAPTER TWO}

\section{A DISCUSSION OF EDUCATIONAL INTERVENTIONS: TRAINING GENERAL PEDIATRIC PRACTICES TO SCREEN FOR DEVELOPMENTAL DISABILITIES}

\section{Background}

\section{Current Detection Rates}

Developmental and behavioral health disorders are now the top five chronic pediatric conditions causing functional impairment (Halfon et al., 2012). In the United States, about one in six children ages 3-17 years has developmental disabilities of varying severity. According to the Centers for Disease Control and Prevention (CDC), developmental disabilities include impairments in physical, learning, language or behavior areas that begin in childhood, impact day-to-day functioning, and typically last throughout a person's lifetime (Centers for Disease Control and Prevention, 2018). It is believed that developmental disabilities are caused by a complex mix of factors including genetics, parental behaviors (such as smoking and drinking during pregnancy), complications during birth, infections during pregnancy or early life, and exposure to environmental toxins, such as lead (Centers for Disease Control and Prevention, 2018). While a combination of hereditary, environmental, and socio-demographic risk factors may compromise a young child's development, early intervention for mental, behavioral, and developmental delays, can mitigate their impact. Children whose developmental concerns remain unidentified face an increased risk for compromised health, safety concerns, and poor psycho-social development (Rice et al., 2014). It is known that 
developmental disabilities are often not identified until after school entrance, increasing the likelihood that the disabilities will persist throughout the school-age years and in to adulthood, and increase the risk of onset of secondary mental health problems often born from school failure (Rice et al., 2014).

\section{The Importance of Early Identification}

National data suggest that only $2-3 \%$ of children identified with developmental disabilities currently receive early intervention services, despite substantial evidence demonstrating that early intervention services produce positive effects regarding developmental outcomes (Bitsko et al., 2016; Centers for Disease Control and Prevention, 2018; Rice et al., 2014). Increasing the use of early intervention services can result in marked reductions in the burden of illness, death and disability, and treatment costs (Yeung et al., 2014). Developmental disabilities have important impacts on society in terms of direct and indirect costs. Considerable resources are expended for the educational, medical, and community support of individuals with developmental delays and conditions (Boyle et al., 2011; Halfon et al., 2012). Affected children have significantly higher rates of healthcare use compared with children without such conditions (Boyle et al., 2011; Halfon et al., 2012). The economic costs to society associated with developmental conditions, including expenditures for additional medical care, and indirect costs related to lost productivity, were estimated to be an average of greater than $\$ 1,000,000$ over the patient's lifetime (Boyle et al., 2011). A system that

promotes the identification of at-risk children can assist in closing the physical, mental and emotional gap between young children who are screened and receive early 
intervention services and those who are not screened and fail to be identified until later childhood.

Several national organizations and programs have developed guidelines and quality care indicators for early screening and identification of developmental concerns or delays in young children (Rice et al., 2014). The Centers for Disease Control and Prevention (CDC), The American Academy of Pediatrics (AAP), and Healthy People 2020 have all endorsed measures for periodic developmental screening of children as indicators of effective and timely population health services (American Academy of Pediatrics, 2006; Centers for Disease Control and Prevention, 2018; Healthy People 2020). Currently, programs are underway that might increase the use of developmental screening in healthcare settings (Guevara et al., 2013). These efforts include initiatives to improve awareness of typical child developmental milestones and indicators of developmental concern, and encourage parents, healthcare providers, and early educators and interventionists to engage in developmental monitoring (Allen, Berry, Brewster, Chalasani, \& Mack, 2010; Daniel et al., 2009; Honigfeld, Chandhok, \& Spiegelman, 2012). Healthcare professionals must be prepared to use valid and reliable screening tools and develop systems of care that screen children early, and link these children to services. Determining ways in which routine developmental screening can be implemented effectively and efficiently is critical to ensure that those in need of early intervention services are referred in a timely manner. 


\section{Context}

General Pediatric Practice and Young Children

In the United States, almost $95 \%$ of children between birth and three years of age report a regular source of healthcare (Centers for Disease Control and Prevention, 2018). The majority of clinical preventative services for infants and children are provided through primary care clinics (Yeung et al., 2014). When general pediatricians collaborate with families and early intervention services, they are able to provide a medical home for young children with, or at risk for, developmental disabilities (Cooley \& McAllister, 2004). Within the medical home approach, high quality and cost-effective health care is provided by the pediatrician who works in a partnership with the family. This care is continuous, coordinated, and comprehensive. Since primary care clinics have frequent contact with infants and young children during critical times in their early development, clinicians at these sites are well suited for the detection of developmental delays in children. This frequent longitudinal contact, unique to primary care, provides pediatricians and clinical staff with important opportunities to conduct screening to detect developmental delays in young children and to initiate early intervention.

\section{Early Detection Policy}

Although nearly all young children have regular primary care visits during which developmental problems could be identified, it is well documented that many pediatricians are failing to identify children in need of early intervention services in a timely manner (Halfon et al., 2004; Jimenez et al., 2014; Rice et al., 2014; Sices et al., 2008; Sices et al., 2004; Zuckerman et al., 2004). In 2001, the American Academy of 
Pediatrics (AAP) announced a new policy statement strongly recommending that all pediatricians begin incorporating the use of standardized, validated developmental screening into their routine clinical practices. These guidelines were written to assist general pediatricians and other pediatric healthcare providers with screening for developmental disabilities and intervening with identified children and their families within the framework of a medical home. Despite the policy implementation in 2001, uptake of use of developmental screening was poor, and several barriers to implementation were reported. Cited barriers included: cost, time, lack of knowledge of standardized developmental screening tools, and lack of manpower to complete periodic screening (Halfon et al., 2004; Sand et al., 2005; Sices et al., 2004). As a result, the guidelines were revised by the AAP in 2006. The 2006 revisions represent the current recommended practice guidelines, and include administration of a standardized developmental screening tool at the 9-, 18-, and 24- or 30-month well-child visits. A total of nine different standardized screening tools were recommended by the AAP (American Academy of Pediatrics, 2006). A summary of the AAP recommendations on developmental surveillance, screening, and referral at well-child checks is presented in Table 6. 


\section{Table 6. AAP Recommended Developmental Screening Schedule}

1. At each visit through the age of 5 years:

- Developmental surveillance

- If concern during surveillance, complete general developmental screening

2. At 9-, 18-, and 24- or 30-months visits:

- General developmental screening with a validated screening tool (all children)

At 18- and 24- or 30-months visits: Autism-specific screening

3. If positive screen result $(1,2$, or 3$)$ :

- Refer child for developmental and medical evaluation

- Refer child to Early Intervention services ( $<3$ years old)

- Refer child to early childhood services ( $\geq 3$ years old)

In the most recent study to date examining the use of standardized developmental screening by general pediatricians, it was found that a mere $55 \%$ of clinicians reported use of validated developmental and autism-specific screening tools within well-child care (Keil et al., 2014). The use of quality screening tools doubles identification rates of children with developmental problems and significantly increases enrollment in needed interventions (Glascoe \& Squires, 2013).

\section{The Expanding Roles of Medical Support Personnel}

The work roles of medical support personnel in healthcare settings are expanding. With developments in medical technology, a push toward evidence-based, patientcentered care, and the need to increase access to primary care, a transformation in healthcare delivery is occurring nationally (Bodenheimer et al., 2014). To comply with these changes, some primary care practices are expanding the roles of registered nurses 
and behavioral health professionals. The clinical workforce in many practices, however, consists of minimally trained, unlicensed medical support staff (Bodenheimer et al., 2014). Despite their lack of formal training, medical support personnel are being tasked with responsibilities such as: tracking lab reports (Naughton et al., 2013); administering vaccines (Ladden et al., 2013); serving as health coaches to improve lifestyle behaviors (Djuric et al., 2017); clinical scribing (Bodenheimer et al., 2014); and screening patients for risky behaviors (smoking, drinking, low physical activity, and unhealthy diet) (Ferrer et al., 2009). Outcomes in studies that have focused on or included the role expansion of medical support personnel have varied, and there is currently a limited understanding as to why there was success in some studies and not in others (Ferrante et al., 2018).

Having a clearer understanding of how to best equip medical support personnel for their changing roles in healthcare is critical to patient care outcomes, and can provide insights into an understudied area of the transformation that is occurring in primary care practice (Bodenheimer et al., 2014; Ferrante et al., 2018).

\section{Evaluation of Educational Interventions}

Evaluation of models of educational interventions for healthcare personnel is necessary so that trainings can be developed and implemented for the benefit of patients. Kirkpatrick's four level evaluation model is a widely used methodology for assessing educational interventions (Kirkpatrick, 1976). The model's four levels are: (1) Reaction; (2) Learning; (3) Behavior; and (4) Results. Level one includes assessment of training participants' reaction to the training program. In practice, measures at this level are most commonly directed at assessing trainees' affective responses to the quality (i.e. satisfaction with the instructor) or the relevance (i.e. work-related utility) of training 
(Kirkpatrick, 1976). Learning measures, level two, are quantifiable indicators of the learning that has taken place during the course of the training (Kirkpatrick, 1976). Level three behavior outcomes address either the extent to which knowledge and skills gained in training are applied on the job or result in increased job-related performance (Kirkpatrick, 1976). Lastly, level four outcomes are intended to provide some measure of the impact that training had on broader organizational goals and objectives (i.e. improved clinical outcomes; improved patient experience; enhanced efficiency; profitability) (Kirkpatrick, 1976). While papers evaluating the impact of educational interventions on healthcare workers beliefs and performance exist, there is a paucity of information in the literature regarding the implementation and evaluation of educational interventions for medical support personnel in pediatric primary care settings, specifically.

This paper aims to examine the role of educational interventions in training healthcare personnel on novel skills in healthcare settings. Specifically, factors that should be considered for an appropriate educational intervention for medical support personnel in pediatric primary care will be identified.

\section{Methods}

A systematic, comprehensive approach was used to conduct a thorough review of the literature. Online public bibliographic databases including PubMed, EBSCO, ProQuest Direct, CINAHL, and Google Scholar were searched to determine target articles. Concepts were derived from these publications, and included a combination of MESH terms and natural language terms. Search terms were broad and included the following: educational interventions; educational models; educational trainings; brief educational training; training; medical support staff; medical support personnel; medical 
assistants; primary care; pediatric primary care; medical home. Searches were conducted until all combinations of terms had been completed. Manuscripts outlining prior educational interventions for healthcare workers were given priority. Hand searches of reference lists of the most relevant articles were completed, as well as reviews of websites and grey literature, until saturation was reached. Articles published after the year 2008 were considered the most relevant. Older manuscripts were included when appropriate and only English-language studies were included. Identified papers were then evaluated using Kirkpatrick's four-level evaluation model to determine if each complied with the four levels necessary for a successful educational intervention. Kirkpatrick's criterion for evaluating educational interventions is listed in Table 7.

Table 7. Kirkpatrick's Four Levels for Evaluating Educational Interventions

\begin{tabular}{|l|l|}
\hline Reaction & How training participants reacted to the intervention \\
\hline Learning & Effect on knowledge, skills, and attitudes \\
\hline Behavior & Extent to which behavior has changed \\
\hline Results & Final results - the impact on patient care \\
\hline
\end{tabular}

\section{Educational Interventions for Healthcare Personnel}

A total of 56 papers were identified in the search, with the majority originating in the United States. Educational training programs were predominately delivered to staff working in residential care facilities and hospitals, and were aimed at physicians, nurse practitioners, nurses, and nursing assistants/aides. In the most recent years, only a handful of manuscripts were found that could be analyzed using Kirkpatrick's 
framework; these include the following trainees and topics: increasing physicians', nurse practitioners', and nurses' knowledge of the HPV vaccine (Berenson, Rahman, Hirth, Rupp, \& Sarpong, 2015); increasing physicians' and nurses' knowledge and comfort levels regarding counseling about breast cancer screening (Bryan, Estrada, Castiglioni, \& Snyder, 2015); increasing nurses' comfort level using tele-ultrasound (Douglas et al., 2019); increasing nurses' knowledge of and response to deteriorating patients (Liaw et al., 2016); determining knowledge and attitudes of nursing assistants about chronic pain in long-term care (Long, 2013); evaluating nurses' attitudes and beliefs about familycentered bedside rounds (Montgomery, Benzies, \& Barnard, 2016); increasing nursing assistants' knowledge of challenging behaviors associated with dementia (Pfeifer, Vandenhouten, Purvis, \& Zupanc, 2018); and improving the ability of nurses to recognize child abuse in the emergency department (Smeekens et al., 2011). A breakdown of the evaluation of these studies using Kirkpatrick's framework is provided below:

\section{Kirkpatrick's Level 1}

Staff Reactions to Training (Liaw et al., 2016)

\section{Kirkpatrick's Level 2}

Knowledge and Understanding (Berenson et al., 2015; Bryan et al., 2015; Douglas et al., 2019; Liaw et al., 2016; Long, 2013; Montgomery et al., 2016; Pfeifer et al., 2018)

Attitudes and Beliefs (Bryan et al., 2015; Long, 2013; Montgomery et al., 2016)

\section{Kirkpatrick's Level 3}

Behavior Change (Smeekens et al., 2011)

\section{Kirkpatrick's Level 4}

$\underline{\text { Results, or Impact (no identified studies) }}$ 
The majority of the most recent research addressing educational interventions for the healthcare workforce has focused on knowledge acquisition and attitudes, outcomes that correspond with the second level of Kirkpatrick's model. To date, few studies have examined the effectiveness of educational interventions on healthcare professionals' behavior, which aligns with level three of Kirkpatrick's model. Some studies exist that used self-reported measures of intention to change behavior, however self-reported intention to change does not necessarily translate into actual behavior change (Liaw et al., 2016; Pfeifer et al., 2018). The only study identified as targeting level three of Kirkpatrick's model, behavior, was by Smeekins et al. (Smeekens et al., 2011). This study demonstrated that a two hour e-learning program improved nurses' $(n=25)$ ability to detect child abuse in an emergency department. The nurses in the intervention $(n=13)$ group demonstrated significantly better questioning techniques and, consequently, higher quality history taking, to determine children who are at risk of child abuse when compared with the control group who received no training at all (Smeekens et al., 2011).

\section{Educational Interventions for Healthcare Personnel on Developmental Screening}

Of the 56 total manuscripts identified in the search, only three manuscripts included educational interventions as components for improved developmental screening practice in pediatric primary care settings. Evaluation of the three manuscripts meeting the proposed inclusion and exclusion criteria follows.

\section{Allen et al., (2010)}

The Enhancing Developmentally Oriented Primary Care (EDOPC) project of the Illinois chapter of the American Academy of Pediatrics and the Illinois Department of Healthcare and Family Services sought to increase primary care providers' use of 
validated tools for developmental screening in children aged 0 to 3 years (Allen et al., 2010). A one-hour educational training program on developmental screening and referral were created and delivered to primary care providers $(n=2873)$ by peer educators (physicians and nurse practitioners) in 164 medical practices throughout Illinois. In addition to the in-person training, study participants received project toolkits containing featured literature, referral information, and sample developmental screening tools. Following the training, participants received access to experts via monthly technical assistance conference calls for support and to monitor practice change. Pre- and posttraining knowledge tests were completed by participants to indicate whether the training had enhanced providers' ability to identify developmental delays and to indicate their intent to screen. Findings indicated that the training was successful in improving the providers' knowledge about screening and referral. Through periodic chart audits of a small group of participating practices $(\sim 10 \%)$ the study also demonstrated that the training was successful in increasing the percentage of providers who intended to implement developmental screening in practice.

$\underline{\text { Evaluation of Allen et al., (2010) }}$

\begin{tabular}{l|c}
\hline \multicolumn{1}{c|}{ Level of Kirkpatrick's Model } & Level Evaluated in Study \\
\hline Kirkpatrick's Level 1: Staff Reactions to Training & No \\
\hline $\begin{array}{l}\text { Kirkpatrick's Level 2: Knowledge and Understanding \& } \\
\text { Attitudes and Beliefs }\end{array}$ & Yes \\
\hline Kirkpatrick's Level 3: Behavior Change & Yes \\
\hline Kirkpatrick's Level 4: Results or Impact & No \\
\hline
\end{tabular}




\section{Bright et al., (2019)}

This project sought to improve care in practice by providing participants with comprehensive training, tools, and support to increase developmental monitoring, screening, and referral for developmental concerns in young children by pediatricians (Bright, Zubler, Boothby, \& Whitaker, 2019). This study also sought to increase the rate of discussion of screening results with families. Pediatricians $(n=32)$ from 25 pediatric practices completed a three-hour in-person training on developmental screening conducted by an expert work group (a multidisciplinary team with backgrounds in pediatric primary care, developmental-behavioral pediatrics, and quality improvement). Participants also received a toolkit with resources from the AAP and CDC, and participated in a group discussion to identify and troubleshoot barriers to implementation. Participants were also asked to complete pre- and post-intervention surveys, participate in monthly webinars, and submit monthly progress reports to describe changes made in developmental screening practices. Some participants were also invited to participate in optional interviews to determine the impact of the project on practice transformation. Findings indicated that the training was successful in increasing the rates of discussions of screening results with families, but no significant change was made in rates of general developmental screening. In interviews, participants reported that they were using a screening tool prior to participating in the current study, but began screening more reliably because of the project, and that as a result of the study, they were more reliably reviewing results with families and more often discussing all results (even normal screens where no parental concerns were reported). When researchers compared physician selfreport with chart review, pediatricians overestimated the extent to which they conducted discussion of developmental screening results. 
Evaluation of Bright et al., (2019)

\begin{tabular}{l|c}
\hline \multicolumn{1}{c|}{ Level of Kirkpatrick's Model } & Level Evaluated in Study \\
\hline Kirkpatrick's Level 1: Staff Reactions to Training & No \\
\hline $\begin{array}{l}\text { Kirkpatrick's Level 2: Knowledge and Understanding \& } \\
\text { Attitudes and Beliefs }\end{array}$ & Yes \\
\hline Kirkpatrick's Level 3: Behavior Change & Yes \\
\hline Kirkpatrick's Level 4: Results or Impact & No \\
\hline
\end{tabular}

\section{Honigfeld et al. (2012)}

The Educating Practices in the Community (EPIC) is a sponsored program of The Child Health and Development Institute of Connecticut (CHDI) that sought to improve developmental screening in child health practices in Connecticut (Honigfeld et al., 2012). A developmental monitoring module was presented by four trained child development specialists in 14 child health sites. Study participants included physician providers and office staff members. The module highlighted information about developmental delays, use of formal developmental screening tools recommended by the AAP, billing codes to ensure reimbursement for developmental screening, and community resources for connecting children to evaluation and intervention services. Following the educational module, participants completed a survey evaluating the information presented. A total of 318 participants completed evaluations, representing a range of office roles: Pediatrician (32\%), Nurse (20\%), Medical Assistant (16\%), Family Physician (9\%), Office Manager (5\%), Other Office Staff (6\%) and Other (11\%). Findings of the post-intervention survey showed that the majority of respondents indicated intent to use the information presented in clinical practice, and indicated that the training was useful. A chart audit at five practices that received the training and five that did not receive the training showed 
higher screening rates in practices that received the training as well as higher rates after the training than before.

Evaluation of Honigfeld et al., (2012)

\begin{tabular}{l|c}
\hline \multicolumn{1}{c|}{ Level of Kirkpatrick's Model } & Level Evaluated in Study \\
\hline Kirkpatrick's Level 1: Staff Reactions to Training & Yes \\
\hline $\begin{array}{l}\text { Kirkpatrick's Level 2: Knowledge and Understanding \& } \\
\text { Attitudes and Beliefs }\end{array}$ & No \\
\hline Kirkpatrick's Level 3: Behavior Change & Yes \\
\hline Kirkpatrick's Level 4: Results or Impact & Yes \\
\hline
\end{tabular}

\section{Discussion}

While limited data have been published, a few recent studies have shown that educational training programs in pediatric primary care settings are beneficial in increasing the knowledge, attitudes, or behaviors of staff on developmental screening (Allen et al., 2010; Honigfeld et al., 2012). Overall, however, these studies fail to meet the criteria outlined by Kirkpatrick's model for a successful intervention at all four levels. There is a paucity of information in the literature regarding educational interventions for healthcare personnel in pediatric primary care settings. An even smaller number of studies of tailored interventions exist, and none have been found that address the abilities of medical support personnel to administer and score a standardized developmental screening tool. Continuous research on educational interventions specific to training medical support personnel on standardized developmental screening tools is important in order to determine the feasibility of this group performing this task. 
The following chapters (three and four) outline the current study parameters and study findings, and seek to not only determine the impact of an educational intervention on medical support personnel's ability to score a developmental screening tool as accurately as the "gold standard", but also report the experience of the medical support personnel learning and applying this newly acquired skill in clinical practice. This study is both timely and important. It seeks to provide a solution to an identified problem. This study's findings can add to the relatively small amount of literature regarding pediatricians' screening practices since the AAP's 2006 mandate by providing detailed and practical answers of how pediatric practices can overcome the perceived barriers to implementation of a standardized developmental screening tool at well-child visits. 


\section{CHAPTER THREE}

\section{THE IMPACT OF AN EDUCATIONAL INTERVENTION ON MEDCIAL SUPPORT PERSONNEL'S KNOWLEDGE OF A DEVELOPENTAL SCREENING TOOL}

\section{Introduction}

The Centers for Disease Control and Prevention (CDC), The American Academy of Pediatrics (AAP), and Healthy People 2020 have all endorsed measures for periodic developmental screening of children as indicators of effective and timely population health services (American Academy of Pediatrics, 2006; Centers for Disease Control and Prevention, 2018; Healthy People 2020). Currently, programs are underway that might

increase the use of developmental screening in healthcare settings (Guevara et al., 2013). These efforts include initiatives to improve awareness of typical child developmental milestones and indicators of developmental concern, and encourage parents, healthcare providers, and early childhood educators and interventionists to engage in developmental monitoring (Daniel et al., 2009). Healthcare professionals must be prepared to use valid and reliable screening tools and develop systems of care that screen children early, and link these children to services. Determining ways in which routine developmental screening can be implemented effectively and efficiently is critical to address the rise in children with developmental disabilities (Zablotsky et al., 2017).

Despite a mandate from the American Academy of Pediatrics in 2006, many general pediatricians are failing to administer a standardized developmental screening 
tool at the 9-, 18-, and 24- or 30-month well-child visits (American Academy of Pediatrics, 2006). In the most recent study to date examining the use of standardized developmental screening by general pediatricians, it was found that a mere $55 \%$ of physicians reported the use of validated developmental and autism-specific screening tools within well-child care (Keil et al., 2014). Barriers to implementation of routine, standardized developmental screening by pediatricians in primary care have been cited and include: cost, time, lack of knowledge of standardized developmental screening tools, and lack of manpower to complete periodic screening (Halfon et al., 2004; Sand et al., 2005; Sices et al., 2004). Specifically, primary care physicians report a lack of selfperceived competency, a desire for education, and a need for improved, specific training in developmental screening (Golnik, Ireland, \& Borowsky, 2009). Facilitators to implementation have also been identified and evaluated; most notably is the expanding roles of medical support personnel (Baker et al., 2010; Bernier, Strobel, \& Lucas, 2018; Bodenheimer et al., 2014; Ferrante et al., 2018). The duration of formal training for medical support personnel, typically at a community college or a commercial training program, varies from three months to two years, with little standardization of curricula, and few programs exist nationally that address the skills needed for expanded roles (Bodenheimer et al., 2014). Despite their lack of formal training, medical support personnel are being tasked to execute many novel tasks in primary healthcare settings. The roles and responsibilities of medical support personnel have changed from a mostly reactive role, completing activities dependent on physician orders during the patient visit and facilitating patient flow through the office, to a more proactive one, conducting pre- 
visit planning, engaging in the overall care for patients, and assisting with population management (Ferrante et al., 2018).

Outcomes in studies that have focused on or included the role expansion of medical support personnel have varied, and there is currently a limited understanding as to why there was success in some studies and not in others (Ferrante et al., 2018). Having a clearer understanding of how to best equip medical support personnel for their changing roles in healthcare is critical to patient care outcomes, and can provide insights into an understudied area of the transformation that is occurring in primary care practice (Bodenheimer et al., 2014; Ferrante et al., 2018). While limited data has been published, a few recent studies have shown that educational training programs in pediatric primary care settings are beneficial in increasing the knowledge, attitudes, or behaviors of staff on developmental screening (Allen et al., 2010; Honigfeld et al., 2012). Overall, however, these studies fail to meet the criteria outlined by Kirkpatrick's model for a successful intervention at all four levels (Kirkpatrick, 1976). Table 8 depicts Kirkpatrick's four levels for evaluating an educational intervention.

Table 8. Kirkpatrick's Four Levels for Evaluating Educational Interventions

\begin{tabular}{|l|l|}
\hline Reaction & $\begin{array}{l}\text { Training participants reaction to the intervention - Was it } \\
\text { acceptable? }\end{array}$ \\
\hline Learning & $\begin{array}{l}\text { Effect on knowledge, skills, and attitudes - What was } \\
\text { acquired? }\end{array}$ \\
\hline Behavior & $\begin{array}{l}\text { Extent to which behavior has changed - How was the learning } \\
\text { applied in practice? }\end{array}$ \\
\hline Results & Final results - What was the effect on patients? \\
\hline
\end{tabular}

Adapted from (Kirkpatrick, 1976)

There is a paucity of information in the literature regarding the implementation and evaluation of educational interventions for medical support personnel in pediatric 
primary care settings. An even smaller number of studies of tailored interventions exist, and none have been found that address the abilities of medical support personnel to administer and score a standardized developmental screening tool. Continuous research on educational interventions specific to training medical support personnel on standardized developmental screening tools is important in order to determine the feasibility of this group performing this task. This study seeks to provide a solution to a problem. The purposes of the present study are to: 1) to determine the impact, before and after, of an educational intervention on medical support personnel's knowledge of administering and scoring a standardized developmental screening tool; and 2) to determine if differences occurred between the scored developmental screening tool response forms of the medical support personnel and the expert scorer.

\section{Methodology}

Research Design

Quantitative descriptive methodology with a one-group pre-test, post-test interventional design will be utilized to determine if an educational intervention provided to medical support personnel will increase their knowledge to administer and score a standardized developmental screening tool. The independent variable is the educational intervention and the dependent variables are the medical support personnel's pre-test knowledge and post-test knowledge. The one-group pre-test, post-test interventional design with a cooling off period is depicted below:

$$
\begin{array}{llll}
\mathrm{O}_{1} & \mathrm{X} & \text { (cooling off period) } & \mathrm{O}_{2}
\end{array}
$$

While a within participants design is a weak design, it was decided for this study because all medical support personnel have to be trained (Creswell, 2009). A cooling off period 
of at least one month is included to reduce bias and to best determine knowledge retention (Bell et al., 2008). The following research question will be answered: To what extent did an educational intervention increase the knowledge of medical support personnel in pediatric primary care settings to administer and score a standardized developmental screening tool?

The second purpose of this manuscript is to determine the impact of the educational intervention on medical support personnel's ability to score the developmental screening tool as accurately as the "gold standard". This research question will be measured quantitatively with a descriptive methodology. The following question will be answered: Did differences occur between the scored developmental screening tool response forms of the medical support personnel and the expert scorer?

For the purposes of this study, the "gold standard" is a doctoral student at the University of Louisville in the Department of Counseling and Human Development, with a concentration in Counseling Psychology. Standardized test user qualifications have been identified by the American Psychological Association (APA). According to these guidelines, test users must have knowledge and skills needed for appropriate test use. It is also important that they have the opportunity to develop and practice their skills. Beyond the psychometric information that students pursuing a doctoral degree in psychology obtain in the classroom, they must also practice their diagnostic skills in clinical settings (APA, 2016). This practice typically begins in graduate school and continues throughout a student's training. Following the completion of their coursework, and after a period of supervised practice, doctoral students in psychology are considered knowledgeable of diagnostic principles and practices (APA, 2016). 


\section{Human Subjects Protection}

This study is conducted in accordance with the Healthcare Information Portability and Accountability Act (HIPPA) regulations. The participants' privacy and confidentiality were maintained. Informed consent was obtained by the researcher, who has completed Protection of Human Subjects Training through the University of Louisville. The informed consent contained all relevant study material including: purpose, background, procedures, benefits, risks, the right to refuse or withdraw from the study, confidentiality, and the contact information of the researcher. The benefit-risk ratio was minimal to no risk and important benefits. The study protocol was submitted to and approved by the Institutional Review Board (IRB) at the University of Louisville (IRB\#: 19.0006).

\section{Setting and Procedures}

A nonprobability convenience sample of 17 medical support personnel (11 licensed practical nurses; 6 medical assistants) were recruited from three urban general pediatric practices in Louisville, KY. No financial compensation for participating in the study was provided, and the medical support personnel received their usual regular hourly salary. The three general pediatric practices included: University of Louisville Pediatrics-Downtown; University of Louisville Pediatrics-Sam Swope Kosair Charities Centre; and University of Louisville Pediatrics-Stonestreet. The procedure included contacting practice managers of the three pediatric clinics to explain the study and also to request permission to attend weekly staff meetings at the clinics. An educational intervention was presented at a weekly staff meeting at each clinic, with clinic practice managers present. The intervention was presented via a PowerPoint presentation where 
audio was prerecorded over the text information shown on the slides. The intervention was completed in this manner so that all medical support personnel could receive the same information, verbatim, and, in the event that medical support personnel were absent on the day of the intervention, they would be able to access the intervention and participate in the study. A brief scoring guide was provided to each participant in the study that included all steps of the administration and scoring process, as well as a workflow chart for implementation of screening in practice. The intervention was also introduced at one monthly University of Louisville Department of Pediatrics division meeting in order for pediatricians and nurse practitioners to receive the same information as their support staff. Data were not collected from the physicians and nurse practitioners, however. A recruitment script was read at the beginning of each staff meeting to introduce the study to participants. Consents were administered at the start of each clinic meeting, and all participants received a copy of the consent. Next, all participants were randomly assigned a study number for use as an identifier throughout the entirety of the study to protect confidentiality. The participant numbers were created by an online number generator. Participants then completed a pre-test and received the intervention during the staff meeting. Over the next two months, study participants administered and scored the developmental screening tools in the clinic. The expert scorer checked each scored screener for accuracy, and recorded errors made by type and by participant number. During data collection, physicians continued to administer the screenings per protocol to not impact patient care. Finally, study participants completed the post-test approximately two months following the intervention at a weekly staff meeting. 


\section{Instrumentation}

Knowledge, Attitude, and Practice Survey

To ensure that behavioral change is sustained, educational interventions need to be evidence-based. Evidence-based programming emphasizes the importance of collecting baseline and follow-up data to design and evaluate activities aimed at populations (World Health Organization, 2008). In this study, a self-report Knowledge, Attitude and Practice (KAP) questionnaire developed by the investigator was administered to participants with instruction. KAP questionnaires are essential in planning, implementing, and evaluating health practices. A well-designed KAP survey can produce data that are informative, insightful, and broadly useful in planning activities for medical support personnel in primary care practice (World Health Organization, 2008). KAP surveys can gather information about what respondents know about a particular health topic or condition, what they think about the health system's response to a health topic or condition, and they can identify needs, problems, and barriers in program delivery, as well as solutions for improving quality and accessibility of services (World Health Organization, 2008). For this study, KAP survey questions included: demographic information; developmental disabilities knowledge and awareness questions; questions regarding attitudes about the administration and scoring of a particular standardized developmental screening tool; and questions about the participants' abilities to administer and score the tool in practice. A copy of the KAP survey is located in Appendix A. 


\section{Educational Intervention}

The educational intervention utilized in this study was administered to medical support personnel at one weekly staff meeting. The intervention lasted approximately 20 minutes, was presented in-person with the assistance of narrated, prerecorded PowerPoint slides, and focused on one AAP-recommended developmental screening tool, the Parents' Evaluation of Developmental Status (PEDS). The PEDS is designed to elicit and address parents' concerns about their child's learning, development, health and behavior. The PEDS is parent-completed. Parents are asked to answer ten (yes/no/a little) questions on the PEDS Response Form. Across the age ranges of the PEDS (birth to eight), the same ten questions are used. There has been a recent increase in the use of the PEDS in pediatric primary care practices compared to other AAP-recommended developmental screening tools owing to its ease of administration and interpretation, and low cost (Hornman et al., 2013; Limbos \& Joyce, 2011; Mackrides \& Ryherd, 2011; Radecki et al., 2011; World Health Organization, 2008). The educational intervention explicitly stated how to administer and score the PEDS. Additionally, a brief scoring guide was provided to each study participant following the conclusion of the in-person training so that they could use the guide as a reference when administering and scoring the PEDS in practice. The intervention outline provided in Table 9 identifies the key objectives of the educational intervention presented to study participants. 


\section{Table 9. Brief Outline of the PEDS Educational Intervention}

Part 1: Review of Developmental Disabilities

- Warning signs and risk factors

- Importance of early screening and intervention

Part 2: Administration of the PEDS

- Potential barriers (language, literacy)

- Engaging the parent

Part 3: Scoring of the PEDS

- Categorizing and totaling parental concerns

- Determining the correct path (referral/no referral)

Part 4: Initiating PEDS in practice

- Workflow map

- Administration and scoring expectations

\section{Data Collection and Analysis}

Data Collection: Part One

Data was collected from pre-test/post-test KAP questionnaires to determine if an educational intervention provided to medical support personnel increased their knowledge to administer and score a standardized developmental screening tool. The pre-test KAP questionnaire was distributed at the weekly staff meeting prior to the administration of the educational intervention. An identical KAP questionnaire was distributed to participants two months after the participants received the educational intervention at a weekly staff meeting. No personal identifiers were on the questionnaires; the participants' assigned study numbers were used. Participants were instructed to answer all questions within a five-minute timeframe to the best of their knowledge. After all participants answered the questionnaire questions, a manila folder was passed around and each participant placed their questionnaire upside down in the 
folder. Following completion of the KAP pre-test, participants received the educational intervention. Participants were then instructed that they would complete the same KAP questionnaire in two months' time.

Results: Part One

Descriptive statistics of the study population and characteristics are presented using means and standard deviations to answer the research question: To what extent did an educational intervention increase the knowledge of medical support personnel in pediatric primary care settings to administer and score a standardized developmental screening tool? Data were entered using the Statistical Package for Social Sciences (SPSS) 25.0 (2017). Paired samples $t$-Test was used as a way to analyze the data to examine any significant changes between the baseline and the post-test knowledge, attitude, and practice scores, and to determine if these scores were different because of participant characteristics. The study used a $p<0.05$ to assess statistical significance.

A total of 17 medical support personnel (11 licensed practical nurses (LPNs); 6 medical assistants (MAs) completed the pre-survey. However, only 13 medical support personnel (9 LPNs; 4 MAs, 76\%) completed the data collection and post-survey phases of the study. Attrition of study participants was attributed to changes in employment and maternity leave. The 13 study participants ranged in age from 21-60 years, with an average age of 37 . Nine study participants indicated that they completed educational training consistent with the level of LPN, and four study participants indicated that they completed educational training consistent with the level of MA. About half of the participants reported three years or less of work experience in their current role (7/13, $54 \%$ ), and about half of the participants reported more than three years of work 
experience in their current role $(6 / 13,46 \%)$. None of the study participants had received any formal training on developmental screening prior to attending the educational intervention.

After the educational intervention, the medical support personnel demonstrated a significant increase $(p<.020)$ on knowledge post-test scores (mean 16.69, SD 2.898) from pre-test scores (mean 14.46, SD 2.961). Analysis of attitude and practice did not reveal statistically significant changes from pre- to post-test; however, these findings should be considered inconclusive owing to the small sample size of participants. Table 10 provides a summary of the KAP survey findings.

Table 10. KAP Survey Findings (N=13)

\begin{tabular}{lccll}
\hline & Mean & $\begin{array}{l}\text { Standard } \\
\text { Deviation }\end{array}$ & $\begin{array}{l}\text { Paired Differences } \\
\text { Mean }\end{array}$ & Significance \\
\hline Knowledge Pre- & 14.46 & 2.961 & & 0.020 \\
Knowledge Post- & 16.69 & 2.898 & -2.231 & \\
Attitude Pre- & 14.69 & 2.594 & & 0.340 \\
Attitude Post- & 15.69 & 2.810 & -1.000 & \\
Practice Pre- & 4.85 & 1.864 & & 0.392 \\
Practice Post- & 5.46 & 1.808 & -0.615 & \\
\hline
\end{tabular}

When controlling for level of education, knowledge pre-post difference remained significant $(p<.025)$ for study participants identified as LPNs (mean 14.11, SD 2.804; mean 16.44, SD 2.920). Analysis of attitude and practice did not reveal statistically significant changes from pre- to post-test for either education group; however, practice for the LPN group was approaching significance. These findings should be considered 
inconclusive owing to the small sample size of participants. Analysis of work experience did not reveal significant changes for knowledge, attitude or practice. These findings, too, should be considered inconclusive owing to the small sample size. Table 11 provides a summary of the KAP survey findings by group education level.

Table 11. KAP Survey Findings by Group Education Level

\begin{tabular}{|c|c|c|c|c|}
\hline & Mean & $\begin{array}{l}\text { Standard } \\
\text { Deviation }\end{array}$ & $\begin{array}{l}\text { Paired Differences } \\
\text { Mean }\end{array}$ & Significance \\
\hline \multicolumn{5}{|l|}{ Education = MA } \\
\hline \multicolumn{5}{|l|}{$(\mathrm{N}=4)$} \\
\hline Knowledge Pre- & 15.25 & 1.797 & & \\
\hline Knowledge Post- & 17.25 & 1.601 & -2.000 & 0.423 \\
\hline Attitude Pre- & 15.00 & 0.707 & & \\
\hline Attitude Post- & 15.25 & 1.315 & -0.250 & 0.789 \\
\hline Practice Pre- & 6.25 & 0.629 & & \\
\hline Practice Post- & 5.50 & 1.258 & 0.750 & 0.718 \\
\hline \multicolumn{5}{|l|}{ Education $=$ LPN } \\
\hline \multicolumn{5}{|l|}{$(\mathrm{N}=9)$} \\
\hline Knowledge Pre- & 14.11 & 2.804 & & \\
\hline Knowledge Post- & 16.44 & 2.920 & -2.333 & 0.025 \\
\hline Attitude Pre- & 14.56 & 3.046 & & \\
\hline Attitude Post- & 15.89 & 3.018 & -1.333 & 0.377 \\
\hline Practice Pre- & 4.22 & 1.787 & & \\
\hline Practice Post- & 5.44 & 1.590 & -1.222 & 0.056 \\
\hline
\end{tabular}




\section{Data Collection: Part Two}

During the two month timeframe between pre- and post-test completion, participants were asked to administer and score 15 Parents' Evaluation of Developmental Status (PEDS) screening forms on clinic patients. Following completion of each screener, participants made copies of the completed PEDS response form and score form, removed any patient identifying information from the copy, and stapled the copied forms together. Participants then added their study number to the top of the copied screening form packet, scored the completed PEDS screener, and placed it in a secured folder. The original PEDS response form in the patient's chart was scored by the physician according to current protocol to not disrupt patient care during the time of the study. The first five screeners that were completed by study participants were immediately checked and scored by the expert scorer to ensure that study participants were scoring the PEDS response forms according to the information presented in the educational intervention. In the event that study participants required refresher training, the prerecorded narrated PowerPoint was re-administered to the participant individually online. Again, it is important to note that during this phase of the study, physicians at each study site continued to administer and score the developmental screeners per current protocol so that patient care and workflow was not disrupted.

\section{Results: Part Two}

Descriptive statistics were utilized to answer the following study question: Did differences occur between the scored developmental screening tool response forms of the medical support personnel and the expert scorer? Five scoring error types were identified by the expert scorer: 1) Participants did not score and tally the total; 2) Participants did 
not circle paths; 3) Participants did not follow up with comments when "yes" or "a little" were circled; 4) Participants did not correctly distinguish comments from categories; and 5) Participants did not fill out all parts of the scoring form. The number and type of scoring errors for all scored screeners $(n=166)$ are presented in Table 12. The largest percentage of errors occurred in study participants not circling paths (40\%) followed by participants not following up with caregivers when "yes" or "a little" were circled (11\%). The smallest errors were found in participants not correctly distinguishing comments from categories (4\%), participants not scoring and tallying the total (3\%), and participants not filling out the entire form (2\%). While it was the most common error committed, participants not circling paths on the score form was determined to be the least impactful error made by the study participants according to the expert scorer. When only this type of error was made, it was determined that the medical support personnel had been mostly successful in correctly categorizing and scoring predictive concerns recorded by caregivers. This is important, as the correct identification of predictive concerns is the purpose of the standardized developmental screening tool (Glascoe, 2005). When participants not circling the correct path was removed as an error type, study participants scored the majority of the screeners as well as the expert scorer $(80 \%)$. 
Table 12. Number and Type of Scoring Errors

$\begin{array}{ccc}\text { Type } & \begin{array}{c}\text { Number of } \\ \text { Errors }\end{array} & \text { Percent } \\ \end{array}$

Did not score and tally total

Did not circle paths

Did not follow up with comments when "yes" or "a little" were circled

Did not correctly distinguish comment from category

Did not fill out the entire form

Form correctly scored - No scoring errors
5

66

18

6

6

4

4

0

0

Because study participants varied in level of education and work experience, additional data analysis was completed to look for group differences. Data was entered using the Statistical Package for Social Sciences (SPSS) 25.0 (2017). A simple $t$-Test was used as a way to analyze the data to identify the differences in mean error rates of study participants between (a) level of education and (b) years of work experience. The Wilcoxon Rank Sum Test was used to evaluate the differences between medians. Data analysis revealed that there were no statistically significant differences in mean error rates between (a) the education groups (medical assistant versus LPN) and (b) the experience groups (less than three years of work experience in current role versus more 
than three years of work experience in current role). These findings were considered to be inconclusive owing to the small sample size in the study $(n=13)$.

The number and type of scoring errors by participant education level and years of experience are reported descriptively, and are presented in Table 13. LPNs made the majority of scoring errors $(77 \%)$, which was expected as there were more LPNs $(n=9)$ in the study than MAs $(\mathrm{N}=4)$. The largest percentage of scoring errors committed by MAs was for not circling paths (52\%). The largest percentage of scoring errors committed by LPNs was for not circling paths (71\%). For years of work experience, study participants with greater than three years of work experience demonstrated the largest percentage of scoring errors for not circling paths (58\%). Study participants with three years of work experience of fewer demonstrated the largest percentage of scoring errors for not circling paths $(73 \%)$. 
Table 13. Number and Type of Scoring Error by Education and Work Experience

\begin{tabular}{|c|c|c|c|c|}
\hline Type & $\begin{array}{l}\text { Number } \\
\text { of Errors }\end{array}$ & $\begin{array}{c}\text { Percent } \\
\text { of Total } \\
\text { Errors }\end{array}$ & $\begin{array}{c}\text { Number of } \\
\text { Errors }\end{array}$ & $\begin{array}{l}\text { Percent } \\
\text { of Total } \\
\text { Errors }\end{array}$ \\
\hline Education Level & MA $(n=4)$ & & $\underline{\operatorname{LPN}(n=9)}$ & \\
\hline Did not score and tally total & 0 & 0 & 5 & 6 \\
\hline Did not circle paths & 12 & 52 & 54 & 71 \\
\hline Did not follow up with comments when & 10 & 44 & 8 & 11 \\
\hline \multicolumn{5}{|l|}{ "yes" or "a little" were circled } \\
\hline $\begin{array}{l}\text { Did not correctly distinguish comment } \\
\text { from category }\end{array}$ & 0 & 0 & 6 & 8 \\
\hline Did not fill out the entire form & 1 & 4 & 3 & 4 \\
\hline Work Experience & $\frac{>3 \text { years }}{\underline{(n=6)}}$ & & $\frac{\leq 3 \text { years }}{(n=7)}$ & \\
\hline Did not score and tally total & 2 & 5 & 3 & 5 \\
\hline Did not circle paths & 23 & 58 & 43 & 73 \\
\hline Did not follow up with comments when & 13 & 32 & 5 & 8 \\
\hline "yes" or "a little" were circled & & & & \\
\hline $\begin{array}{l}\text { Did not correctly distinguish comment } \\
\text { from category }\end{array}$ & 0 & 0 & 6 & 10 \\
\hline Did not fill out the entire form & 2 & 5 & 2 & 4 \\
\hline
\end{tabular}

Table 14 depicts the calculated error rates of the LPNs and MAs, with the LPNs having a higher rate of errors in scoring as a group, and of years of work experience, with 
those having worked greater than three years having a higher rate of scoring errors as a group.

Table 14. Calculated Error Rate by Education and Years of Work Experience

\begin{tabular}{|c|c|c|}
\hline Group & Total Scoring Errors & Calculated Error Rate \\
\hline LPN $(\boldsymbol{n}=\mathbf{9})$ & 76 & 8.44 \\
\hline MA $(\boldsymbol{n}=\mathbf{4})$ & 23 & 5.75 \\
\hline$>$ 3 years of work & 40 & \\
experience $(\boldsymbol{n}=\mathbf{6})$ & & \\
\hline < 3 years of work & 59 & \\
experience $(\boldsymbol{n}=\mathbf{7})$ & & \\
\hline
\end{tabular}

\section{Discussion}

The aims of the current study were: 1) to determine the impact of an educational intervention on the knowledge of medical support personnel in pediatric primary care settings to administer and score a standardized developmental screening tool; and 2) to determine the impact of the educational intervention on medical support personnel's ability to score the developmental screening tool as accurately as the "gold standard". Specifically, the investigator wanted to determine if the educational intervention would increase the knowledge level of medical support personnel to administer and score a developmental screening tool, and to determine if differences occurred between the 
scored developmental screening tool response forms of the medical support personnel and the expert scorer.

An attempt to answer a study question using quantitative methodology with medical support personnel's knowledge was done with this project. Statistical significance was achieved with data analysis. Clinical significance was achieved after the educational intervention as evidenced by an increase in medical support personnel's ability to score a standardized developmental screening tool similar to the "gold standard". The data gathered for this study demonstrated that the educational intervention was successful in significantly increasing the knowledge level of medical support personnel to administer and score a standardized developmental screening tool $(p<.020)$. Further, the data showed that the medical support personnel were able to score the standardized developmental screening tool and correctly identify concerns predictive of developmental disabilities with accuracy similar to that of the expert scorer $(80 \%)$

The roles of medical support personnel are changing, and having a clearer understanding of how to best equip medical support personnel for their changing roles in healthcare is critical to patient care outcomes (Bodenheimer et al., 2014; Ferrante et al., 2018). Educational interventions have been utilized to assist medical support personnel to acquire new work-related skills. There is currently a limited understanding as to why there was success in some studies of educational interventions for medical support personnel and not in others, however (Ferrante et al., 2018).

The findings of this study are similar to the few other recent studies that have shown that educational training programs in pediatric primary care settings are beneficial 
in increasing the knowledge, attitudes, or behaviors of staff on developmental screening (Allen et al., 2010; Honigfeld et al., 2012). Overall, however, these recent studies fail to meet the criteria outlined by Kirkpatrick's model for a successful intervention at all four levels (Kirkpatrick, 1976). When evaluating the current study using Kirkpatrick's model, the results of the quantitative study findings address Levels 2 (Knowledge and Understanding and Attitudes and Beliefs) and 3 (Behavior Change) of the evaluation framework. Specifically, Level 2 was addressed in this study by comparing the KAP preand post-test responses of the medical support personnel. Level 3 was addressed in this study by comparing the scored developmental screening tools of the medical support personnel to those of the expert scorer. To address Levels 1 (Staff Reaction to Training) and 4 (Impact on Patient Care), additional data were collected.

The following chapter (four) seeks to report the experience of the medical support personnel learning and applying this newly acquired skill in clinical practice. Self-report of the impact on patient care is also discussed. This study is both timely and important. It seeks to provide a solution to an identified problem. This study's findings can add to the relatively small amount of literature regarding pediatricians' screening practices since the AAP's 2006 recommendations by providing detailed and practical answers of how pediatric practices can overcome the perceived barriers to implementation of a standardized developmental screening tool at well-child visits. 


\section{CHAPTER FOUR}

\section{THE EXPERIENCE OF MEDICAL SUPPORT PERSONNEL LEARNING AND APPLYING A NEWLY ACQUIRED CLINICAL SKILL}

\section{Background}

Developmental screening can be done by a number of professionals in health care, community, and school settings. However, primary health care providers are in a unique position to promote children's developmental health. In the United States, almost $95 \%$ of children between birth and three years of age report a regular source of healthcare (Centers for Disease Control and Prevention, 2018). The majority of clinical preventative services for infants and children are provided through primary care clinics (Yeung et al., 2014). When general pediatricians collaborate with families and early intervention services, they are able to provide a medical home for young children with, or at risk for, developmental disabilities (Cooley \& McAllister, 2004). Within the medical home approach, high quality and cost-effective health care is provided by the pediatrician who works in a partnership with the family. This care is continuous, coordinated, and comprehensive. Since primary care clinics have frequent contact with infants and young children during critical times in their early development, clinicians at these sites are well suited for the detection of developmental delays in children. This frequent longitudinal contact, unique to primary care, provides pediatricians and clinical staff with important opportunities to conduct screening to detect developmental delays in young children and to initiate early intervention. Healthcare professionals must be prepared to use valid and 
reliable screening tools and develop systems of care that screen children early, linking these children to services. Determining ways in which routine developmental screening can be implemented effectively and efficiently is critical.

Integrating routine developmental screening into the practice setting can seem daunting. Historically, the burden of completing routine developmental screening for young children at well-child visits has fallen on the primary care physician. Currently, the roles of medical support personnel are expanding. Despite their lack of formal training, medical support personnel are required to execute many novel tasks in primary healthcare settings such as: tracking lab reports (Naughton et al., 2013); administering vaccines (Ladden et al., 2013); serving as health coaches to improve lifestyle behaviors (Djuric et al., 2017); clinical scribing (Bodenheimer et al., 2014); and screening patients for risky behaviors (smoking, drinking, low physical activity, and unhealthy diet) (Ferrer et al., 2009). Outcomes in studies that have focused on or included the role expansion of medical support personnel have varied, and there is currently a limited understanding as to why there was success in some studies and not in others (Ferrante et al., 2018).

Having a clearer understanding of how to best equip medical support personnel for their changing roles in healthcare is critical to patient care outcomes, and can provide insights into an understudied area of the transformation that is occurring in primary care practice (Bodenheimer et al., 2014; Ferrante et al., 2018).

The roles and responsibilities of medical support personnel have changed from a mostly reactive role, completing activities dependent on physician orders during the patient visit and facilitating patient flow through the office, to a more proactive one, conducting pre-visit planning, engaging in the overall care for patients, and assisting with 
population management (Ferrante et al., 2018). The expanding the roles of medical support personnel to assist in the administration and scoring of screening tools has been identified in the research (Baker et al., 2010; Bernier et al., 2018; Bodenheimer et al., 2014; Ferrante et al., 2018). In the most recent study to date, medical assistants were reportedly positive about their role shifts and role expansion when they: 1) understood how their responsibilities fit within broader practice transformation goals; 2 ) received formal training on new tasks; and 3) had open communication with clinicians and practice leaders about both the role expectation changes and the newly learned skills (Ferrante et al., 2018).

While limited data have been published, a few recent studies have shown that educational training programs in pediatric primary care settings are beneficial in increasing the knowledge, attitudes, or behaviors of staff on developmental screening (Allen et al., 2010; Honigfeld et al., 2012). Less in known, however, about whether what is taught in the educational intervention is carried over and implemented into clinical practice effectively. In fact, many of the reported studies only address one or two levels of Kirkpatrick's four-level model of evaluation, and therefore do not meet the criteria outlined by Kirkpatrick's model for a successful intervention (Allen et al., 2010; Glascoe, 2005; Honigfeld et al., 2012). Table 15 depicts Kirkpatrick's four levels for evaluating an educational intervention. 
Table 15. Kirkpatrick's Four Levels for Evaluating Educational Interventions

\begin{tabular}{|l|l|}
\hline Reaction & $\begin{array}{l}\text { Training participants reaction to the intervention - Was it } \\
\text { acceptable? }\end{array}$ \\
\hline Learning & $\begin{array}{l}\text { Effect on knowledge, skills, and attitudes - What was } \\
\text { acquired? }\end{array}$ \\
\hline Behavior & $\begin{array}{l}\text { Extent to which behavior has changed - How was the learning } \\
\text { applied in practice? }\end{array}$ \\
\hline Results & Final results - What was the impact on patients/patient care? \\
\hline
\end{tabular}

Adapted from (Kirkpatrick, 1976)

The purpose of the present study is to report the experiences of medical support personnel learning a newly acquired skill, and the application of that learned skill in clinical practice. Specifically, Levels 1 (Reaction) and 4 (Results) of Kirkpatrick's model will be discussed and evaluated through the lens' of the participants. The following study question will be answered: What was the experience of medical support personnel in learning and applying a newly acquired skill in clinical practice?

\section{Methodology}

\section{Research Design}

Qualitative inquiry is appropriate for exploring human behavior, thoughts, emotions, and experiences (Brinkman \& Kvale, 2015). Quantitative data cannot provide the essence of experience. In this study, a qualitative approach was selected because this study sought to obtain descriptions of experiences of medical support personnel through interviews about their learning of a newly acquired skill, and the application of that skill in clinical practice.

Interviews provide interviewees with the context to express their reality (Brinkman \& Kvale, 2015). An interview methodology is recommended to understand how individuals construct meaning of reality and of the lived experience (Roulston, 
2010). Interviews can be a vital tool because researchers can gather in-depth qualitative data from medical support personnel regarding their experiences learning and applying new clinical skills. The interview orientation for this study was based on a romantic view. A romantic interview perspective aims to develop an honest interaction between the interviewee and the interviewer (Roulston, 2010). The purpose of utilizing romantic orientation in interviews is to make participants feel comfortable so that they can express their thoughts, feelings, and experiences clearly (Roulston, 2010). Utilizing the romantic approach in interviews, “... makes the interview more honest, morally sound, and reliable, because it treats the respondent as an equal, allows him or her to express personal feelings, and therefore presents a more realistic picture than can be uncovered using traditional interview methods" (Fontana \& Frey, 1994, p.371). Since there are no studies that report the experiences of medical support personnel learning to score a developmental screening tool, a thematic analysis approach was applied (Braun \& Clarke, 2006).

Thematic analysis is a method for identifying, analyzing, and reporting patterns or themes within data. Thematic analysis, “...minimally organizes and describes...data in rich detail" (Braun \& Clarke, 2006, p.79). An inductive approach in thematic analysis means that the themes that are identified are strongly linked to the data themselves. It is a process of coding data that allows for themes to emerge from the data, and does not try to fit the data in to a pre-existing coding frame, or the researcher's preconceptions (Braun \& Clarke, 2006). The five phases of thematic analysis and description of the analytic process are listed in Table 16. 
Table 16. Phases of Thematic Analysis

\begin{tabular}{|l|l|}
\hline Phase & \multicolumn{1}{|c|}{ Description of the Process } \\
\hline $\begin{array}{l}\text { 1. Familiarizing yourself } \\
\text { with your data }\end{array}$ & $\begin{array}{l}\text { Transcribing data, reading and re-reading the data, writing } \\
\text { down initial ideas }\end{array}$ \\
\hline 2. Generating initial codes & $\begin{array}{l}\text { Coding interesting features of the data in a systematic way } \\
\text { across the entire data set; collecting data relevant to each } \\
\text { code }\end{array}$ \\
\hline 3. Searching for themes & $\begin{array}{l}\text { Collating codes into potential themes; gathering all data } \\
\text { relevant to each potential theme }\end{array}$ \\
\hline 4. Reviewing themes & $\begin{array}{l}\text { Checking if the themes work in relation to the coded } \\
\text { extracts and the entire data set }\end{array}$ \\
\hline $\begin{array}{l}\text { 5. Defining and naming } \\
\text { themes }\end{array}$ & $\begin{array}{l}\text { Ongoing analysis to refine the specifics of each theme, and } \\
\text { the overall story the analysis tells }\end{array}$ \\
\hline 6. Producing the report & $\begin{array}{l}\text { Selection of vivid, compelling extract examples; relating the } \\
\text { analysis back to the research question(s) and the literature; } \\
\text { producing a scholarly report of the analysis }\end{array}$ \\
\hline \multicolumn{2}{|l|}{ Adapted from (Braun \& Clarke, 2006) }
\end{tabular}

Human Subjects Protection

This study is conducted in accordance with the Healthcare Information Portability and Accountability Act (HIPPA) regulations. The participants' privacy and confidentiality were maintained. Informed consent was obtained by the researcher, who has completed Protection of Human Subjects Training through the University of Louisville. The informed consent contained all relevant study material including: purpose, background, procedures, benefits, risks, the right to refuse or withdraw from the study, confidentiality, and the contact information of the researcher. The benefit-risk ratio was minimal to no risk and important benefits. The study protocol was submitted to 
and approved by the Institutional Review Board (IRB) at the University of Louisville (IRB\#: 19.0006).

\section{Setting and Procedures}

The qualitative model of data collection and analysis allows for a small sample size because a unique and individual experience is being studied (Creswell, 2013). For this study, three study participants were sought. The three study participants were selected from a total of 13 medical support personnel from three urban general pediatric practices in Louisville, KY using purposeful sampling: University of Louisville Pediatrics-Downtown; University of Louisville Pediatrics-Sam Swope Kosair Charities Centre; and University of Louisville Pediatrics-Stonestreet. Study participants had recently completed an educational intervention about standardized developmental screening, and completed an application period of approximately two months where each participant administered and scored standardized developmental screening tools on live patients in clinic. One study participant was selected from each practice. Selection was based on medical support personnel who had participated in the study in sufficient amounts so that they were able to recall, discuss, and articulate their experience with the educational intervention, and with administering and scoring the standardized developmental screening tool on live patients. For this study, the medical support staff member who had administered and scored the most screening tools at each site $(\mathrm{N}=>15)$ was selected.

Following completion of an educational intervention and pre- and post-test measures, an in-depth interview with each of the three study participants was completed. Interview questions were derived from responses provided by the study participants on 
the post-test measure, and included questions targeting all four levels of Kirkpatrick's Model. Detailed interviews were conducted individually--one interview at each of the three urban general pediatric practices. While interview questions were prepared, the investigator operated under a flexible approach, and was responsive to each of the three study participants, offering open-ended questioning, and adjusting the procedures as the situation dictated (Creswell, 2013). A copy of the interview protocol is located in Appendix B.

\section{Data Collection}

Data was collected on three separate occasions, as the three in-depth interviews were completed individually. The researcher completed all components of data collection independently, and a research assistant was not utilized to conduct the interviews. Descriptions of experiences were recorded from each of the three study participants. The interviews were audio-taped, lasting 20-30 minutes each. The audio tapes were later transcribed. In keeping with tenets of the romantic approach to interviewing, the first five minutes of each interview was spent talking with the medical support personnel about their days at work in effort to reduce stress. Talking with the study participants and treating them with full respect allowed the interviewer to feel comfortable asking interview protocol questions, and enabled the study participants to engage and to answer all interview questions posed to them (Roulston, 2010). Freehand writing observations, notes, and verbatim responses were also recorded on a notepad. The collecting of direct quotes through the written documentation and audio transcription was beneficial in the analysis and in reporting of the results. This provided what 
Roulston (2010) describes as gathering an awareness of the "lived sense" of an individual's experience.

\section{Data Analysis}

The in-depth interviews were transcribed verbatim, and the transcribed text was compared with the handwritten notes for consistency. Since there are no studies that report the experiences of medical support personnel learning to score a developmental screening tool, a thematic analysis approach was applied (Braun \& Clarke, 2006). Thematic analysis was used to analyze the interviews. Thematic analysis aims to present the meaning and experience that address the reality of each individual (Braun \& Clarke, 2006). To establish the themes, the researcher read the transcripts multiple times and summarized the information to find the main points related to the study. Next, interviews were coded according to ideas that came from the questions answered by the interviewees. The themes in the study were identified based on their consistency-ideas that were constant across the experiences of the medical support personnel, and across settings, and on their relationship to the research questions. Once the main themes were identified, the transcripts were reviewed for additional assignment of coded text to the thematic areas. Finally, direct quotes from participants were extracted from the transcripts to provide vivid, compelling examples to be included in the final analysis (Braun \& Clarke, 2006).

\section{Ethical Considerations}

Trustworthiness and credibility are critical parts of qualitative research. In this study, trustworthiness was established through purposeful sampling. One participant was 
selected and interviewed from each of the three pediatric clinics to ensure that those selected were representative of the larger group. Additionally, interviewees who had completed the largest number of developmental screening tools at each clinic was chosen to make sure that the information presented in the study was from medical support personnel who had the most experience with the tasks being reported.

Peer debriefing was considered to ensure the credibility of the study. A doctoral student in psychology who demonstrated knowledge in the field, as well as in qualitative research completed this process. Emerging themes were reviewed by the peer, and the peer assured that the themes were clear to understand. Feedback was considered, which also enhanced the credibility and confirmed the validity of the study.

Results

Analysis of medical support personnel's reflections on their experience with the educational intervention and application of the information presented in the intervention resulted in four main categories: "Acceptability of the Training"; "Enablers to Implementation"; “Obstacles/Barriers to Implementation"; and "Evidence of Impact", each of which were derived from the themes that emerged during data analysis. Each category is presented separately. Under the respective headings, the content of each category is described and illustrated using direct quotes from participants noted in italics.

\section{Acceptability of the Training}

The category Acceptability of the Training represented participant descriptions of the training being enlightening, and provided logistical aspects of the training that participants felt were conducive to their current work day. The medical support 
personnel spoke fondly of the education intervention. All participants identified aspects of the training that they felt were conducive to learning, and aided in increasing their understanding of standardized developmental screening. Participants reported:

The training was very informative. I really did not have any contact with the PEDS forms other than just making sure they got to the physicians. So, I was able to understand exactly what they were...the reasoning for them.

It was good. I followed along. I was getting the concept of what we were doing and understanding how we were supposed to screen and complete the response forms and scoring sheets and everything. It was really good.

I got all the information...Any time there's anything that we can do that will help patient care, and help me to learn to be able to take care of them better, that's what I like.

It was laid out very well. The description of what each line meant and how to follow was laid out very well to actually get to the score that you are trying to score. I did fully understand and any questions were answered.

Participants also offered insight into preferred logistical aspects of the training. Some participant comments were:

It was short and to the point. That was the best part. I thought it would be a long and drawn out process which it wasn't. So, quite surprised with that.

I actually would have liked it to be a little bit longer. I know it was the end of the day and everybody was trying to hurry and get out of here. Sometimes rush is not good because you forget to be able to ask your questions.

I expected something boring but after the training I knew that it was going to be something to help the patient and the doctors. It was over lunch, so that worked out great!

\section{Enablers to Implementation}

The category Enablers to Implementation represented participant descriptions of factors that made the testing of their knowledge and skills easy and flexible, as well as factors that contributed to their self-confidence and motivation to complete the 
administration and scoring of the screeners in clinical practice. All participants reported that two key factors contributed to their being able to administer and score the standardized developmental screening tool in practice. The two key factors were: 1) asking other staff in the clinic for assistance; and 2) using the PEDS Brief Scoring Guide that was provided to study participants at the end of the educational intervention. Participants reported:

It was really nice that we had a handout to where we could refer back to if we had any questions...showing how people answered and then how you took that and applied it...this is the way that you could look at it to try to answer your questions.

...it gave me a beginning of what to do and then it gave me something to fall back on when people weren't here for me to be able to ask my questions, and if I forgot.

There were a couple that I was a little not sure on how to score it, so I made my assumptions and then I just went to one of the physicians and said, "Is this how you would score it?"... and they just looked at it and said, "Yes, you've scored it appropriately."

I had some questions on it but we discussed it between maybe one other person and then came back to the guide again and we followed the guide.

... But most of the time they were coming to me asking for help...It felt good to know that they actually trust to come to me for help doing it.

When asked the questions, "Based on your experience, do you feel more confident in administering and scoring the PEDS?” and, "What factors do you think most help you know how to administer and score the PEDS?" study participants reported that they felt more confident administering and scoring the standardized screening tool if having the Brief Scoring Guide to use as a reference, and with practice.

Yes I feel more confident. I was not scoring before...but I feel confident that I could as long as I had the guide with me.

Yes! I felt confident of giving the PEDS form and making sure that it was taken care of if I saw maybe a physician had missed the scoring part, to go ahead and score. I had no problem with doing that. My initial fear was like, "Oh no. What if I put 
something on there and I score this kid wrong and they really needed this help and I didn't mark them as needing that?" Afterward, I feel better in that if it's all no concerns, okay, that's good. If there's anything marked then that leads me, "Okay, then I can ask this and I can ask this."

Yes! I definitely feel more confident in scoring the PEDS than in the beginning. I think by doing the training, having the book and repetitive doing it makes you feel better. It makes you feel more comfortable.

\section{Obstacles/Barriers to Implementation}

The category Obstacles/Barriers to Implementation represented participant responses that offered insight into factors that made administration and scoring of the tool difficult to implement in practice. A commonly reported barrier to the medical support personnel administering and scoring the standardized developmental tool was the interpretation of caregiver report by the study participants. Specific concerns regarding the administration and scoring of screeners that were completed by caregivers who did not speak English as their primary language were also reported. Participant accounts of their experiences with these types of barrier were as follows:

I guess I wondered if they were actually being honest. Some people don't want to think that their child does have a problem. It was, "Are the parents answering these questions correctly? Do they really and truly understand what the questions are asking? Did I make it understandable to what they're supposed to do?

Some ways in how a parent will answer a question is a little hard to interpret. Then I actually...had one who was Spanish, spoke pretty good English but not the greatest. At the top or bottom they had all this stuff written in Spanish. I'm like, "Okay, I don't know what that means." I tried to ask on that one and got some information but wasn't quite sure I was interpreting correctly.

Barriers are language barriers. We have these Hispanic families who come in here and we do have the thing in Spanish, but then to be able to talk to them and say, "I don't do Spanish." We have families that come in here that speak French. We have Somali. We have a lot of those that we don't even have those forms in those languages.

Some of them, it was a language barrier because they were Spanish. I try to look through the pamphlet you gave us to figure out where to put it at. Then sometimes it would be the parent wouldn't really put a good enough comment on what the concern really was. So it was hard. 
A second commonly reported barrier centered on staff buy-in and lack of communication between staff members and between staff members and caregivers. When asked what kind of support would be important to continue to administer the PEDS, one participant said:

That everybody is on board. Doctors are on board with it, all of the nursing staff is on board, that everybody knows that we need to score these and it's very important.

Other comments included: have to do."

A lot of coworkers didn't want to drop it. They just felt, "It's one more thing we

I think there needs to be a better process between the front people who are working the kids up and the back people that are doing the immunizations and lab work. These are all duties we do and we now do the screening. Somehow there needs to be more communication I guess.

I think there has to be more interaction between the staff and the parents and filling out the form.

A final barrier that was reported by all participants was time. Participant reported:

...it's very busy. Sometimes they don't have the forms filled out beforehand even though they should. They've got kids running around like crazy and they don't have the time to do that and then we don't have time.

It gave me more to do. It does add a new procedure to do the follow up on. And, depending on the day how much you can do, how much you can't do...I would hope that we would have more time to where we could...not feel rushed. I think we will just have to come up with some ways to try to put it with the normal process that we do, like a normal routine.

If we were to actually make sure it was scored, that would be taking a little more time to do that because...we're a fast clinic. We're busy and we 're fast. We would just need a little more time at that process. 


\section{Evidence of Impact}

The category Evidence of Impact represented participant thoughts on their overall experience learning and applying a new skill in practice. Responses to the question, "What are your suggestions for how to make sure that young children are identified with developmental disabilities as early as possible?" were also included here, as participant responses offered insight in to how the educational intervention may have impacted patient care both during the time of the study, and in future practice. Participants reported:

It made me feel good. We could really get a grasp on if this child had a learning disability or potentially help them get some help. Maybe it might not be as severe a disability as it could have been.

Before it was just something you gave them and they filled out. In my line, you never looked at it. So...now you're being more informed about the kids that you're taking care of and their concerns.

I learned that I need to be more observant. To explain the sheet better to the parents as we give it to them. At first I was just, "Here, you need to fill out this form." I wasn't saying, "Well if there are any concerns, please write the comments down of what you're concerned about." Now we get a better knowledge of what they are concerned about...I'm actually saying, "This is about behavior, learning disabilities. If you feel your child has any of these and you circle yes or no, please comment on what your concerns are for us so that we can know."

I liked that we got to see if there were any areas that the kids might be struggling in, or knowing the thought process of the parents... I liked being able to help the doctors know that there is a real concern and a real scoring sheet to this.

Participants offered the following on the use of the PEDS form, specifically.

The PEDS form is a good one. Us, as workers here, we see the kids. Not every kid is going to show signs, but we now know those big signs that are like, "Wait a minute. Usually at this age they're doing this and that." We can always relay it to the doctors and be like, "When I was triaging them they didn't do the normal thing." 
I believe the PEDS form is a good---no, I think that's a great thing. They needed to get started as soon as possible in any support that they need in that area...I think that form being handed out at an early age is helping.

\section{Discussion}

The current study reported the experiences of medical support personnel learning a newly acquired skill, and the application of that learned skill in clinical practice. Indepth interviews were completed with three study participants who had recently completed an educational intervention on standardized developmental screening pediatric primary care to answer the question: What was the experience of medical support personnel in learning and applying a newly acquired skill in clinical practice?

Analysis of medical support personnel's reflections on their experience with the educational intervention and application of the information presented in the intervention resulted in four main categories: "Acceptability of the Training"; "Enablers to Implementation"; "Obstacles/Barriers to Implementation"; and "Evidence of Impact". First, study participants reported that the educational intervention was acceptable and informative, and aided in their understanding of developmental screening. Study participants also offered insight in to aspects of the intervention and subsequent practice that enabled them to implement developmental screening in clinical practice. Both the assistance of the Brief Scoring Guide and corroboration with colleagues, and factors that motivated the participants to complete this new work process were identified. However, study participants also reported obstacles to implementing developmental screening smoothly. Time, poor communication between clinic staff, and interpretation of caregiver report of developmental concerns were all indicated as barriers to implementation. Finally, the interviews revealed that participants felt that their role in 
the implementation of developmental screening had a positive impact on helping to identify children with, or at risk for, developmental delays.

Using Kirkpatrick's model as a guide throughout the study, special attention was given to the personal accounts of medical support personnel that corresponded to Levels 1 (Reaction) and 4 (Results) of Kirkpatrick's model during analysis of the data. While many important themes emerged though analysis of the data, most notable were the participants' reactions to the training, and their self-report of the impact on patient care. Report of impact of the educational intervention on both was positive at both levels of the model. Although self-report may not be considered the most robust means to measure impact on patient care, because of the short timeline for this study, it does provide a way for the effect on patients to be examined.

While some research exists to show that educational training programs in pediatric primary care settings are beneficial in increasing the knowledge, attitudes, or behaviors of staff on developmental screening, this is believed to be the first study to report if what was taught in an educational intervention on developmental screening was carried over and implemented into clinical practice effectively by medical support personnel in pediatric primary care. This study is both timely and important. It provides a potential solution to an identified problem. This study's findings can add to the relatively small amount of literature regarding pediatricians' screening practices since the AAP's 2006 recommendations by providing detailed and practical answers of how pediatric practices can overcome the perceived barriers to implementation of a standardized developmental screening tool at well-child visits. 
The previous chapters (two, three, and four) have provided a review of the literature on educational interventions to train medical support personnel, and outlined the current study parameters and study findings. This study sought to not only determine the impact of an educational intervention on medical support personnel's ability to score a developmental screening tool as accurately as the "gold standard", but also report the experience of the medical support personnel learning and applying this newly acquired skill in clinical practice. The following chapter (five) provides a discussion of the major findings of all components of the study, study limitations, implications for future practice, and the overall contribution of this study's findings to the practice of health practitioners. 


\section{CHAPTER FIVE}

\section{DISCUSSION}

Developmental delays are common in early childhood, and are predictive of later learning and behavioral difficulties. Early treatment of developmental delays leads to improved outcomes for children (Yeung et al., 2014). In order to benefit from early intervention, children with developmental delays must be identified and referred at a young age. General pediatricians have the opportunity to monitor young children's development during well-child visits between birth and age five, and are trained in child development and behavior; therefore they are ideally suited to identify developmental delays. Use of validated developmental screening tools is supported by American Academy of Pediatrics (AAP) guidelines, but these instruments are used variably and inconsistently by general physicians in pediatric practice (King et al., 2010). Children are currently not being identified in a timely manner, and are therefore not accessing early intervention services.

Because of the expanding work roles of medical support personnel, it was worthwhile to determine if this group could administer and score a developmental screening tool after completing an educational intervention to assist general pediatric practices in using these tools in accordance with the AAP mandate, and enrolling more young children into early intervention services. Guided by Kirkpatrick’s four-level evaluation model, the current study proposed: 1) to assess the effect of an educational intervention to increase the knowledge of medical support personnel in pediatric primary 
care settings on the administration and scoring of a standardized developmental screening tool; 2) to determine if the medical support personnel were able to score the selected tool in practice as accurately as the "gold standard"; and 3) to report the medical support personnel's experience of learning and applying a newly acquired skill in clinical practice. The following provides a discussion of the project and its' findings, implications for practice, study limitations, and the overall contribution of this study's findings to health practice in pediatric primary care.

\section{Summary of the Project}

The aim of this study was to determine the impact of an educational intervention on medical support personnel's knowledge to administer and score a standardized developmental screening tool. Three research questions guided this study: 1) To what extent did an educational intervention increase the knowledge of medical support personnel in pediatric primary care settings to administer and score a standardized developmental screening tool?; 2) Did differences occur between the scored developmental screening tool response forms of the medical support personnel and the expert scorer?; and 3) What was the experience of medical support personnel in learning and applying a newly acquired skill in clinical practice? A three manuscript format was utilized to report the components of the study.

This project attempts to answer a research question regarding medical support personnel's knowledge of developmental screening, using quantitative and qualitative methodology. Statistical significance was achieved with data analysis. Clinical significance was achieved as evidenced by the medical support personnel's ability to administer and score a standardized developmental screening tool similar to the "gold 
standard" in clinical practice, and through the reported impact that implementation of developmental screening by this group had on patient care in practice.

Manuscript One was presented in Chapter Two, and provided a synthesis of the literature surrounding the role educational interventions play in training healthcare personnel on novel skills in healthcare settings. Review of the literature found a few recent studies that reported that educational training programs in pediatric primary care settings were beneficial in increasing the knowledge, attitudes, or behaviors of staff on developmental screening (Allen et al., 2010; Honigfeld et al., 2012). Overall, however, those studies failed to meet the criteria outlined by Kirkpatrick's model for a successful intervention at all four levels. There was a paucity of information in the literature regarding educational interventions for healthcare personnel in pediatric primary care settings. An even smaller number of studies of tailored interventions were found to exist, and none were found that addressed the abilities of medical support personnel to administer and score a standardized developmental screening tool.

Manuscript Two was presented in Chapter Three, and utilized a one-group pretest, post-test interventional design to determine the impact, before and after, of an educational intervention on medical support personnel's knowledge of administering and scoring a standardized developmental screening tool. This chapter also sought to determine the impact of the educational intervention on medical support personnel's ability to score the developmental screening tool as accurately as the "gold standard". The data gathered for this study demonstrated that the educational intervention was successful in significantly increasing the knowledge level of medical support personnel to administer and score a standardized developmental screening tool $(p<.020)$. Further, the 
data showed that the medical support personnel were able to score the standardized developmental screening tool and correctly identify concerns predictive of developmental disabilities with accuracy similar to that of the expert scorer (80\%).

The findings of this study were similar to the few other recent studies that have shown that educational training programs in pediatric primary care settings are beneficial in increasing the knowledge, attitudes, or behaviors of staff on developmental screening (Allen et al., 2010; Honigfeld et al., 2012). When evaluating the current study using Kirkpatrick's model, the results of the quantitative study findings address Levels 2 (Knowledge and Understanding and Attitudes and Beliefs) and 3 (Behavior Change) of the evaluation framework. Specifically, Level 2 was addressed in this study by comparing the KAP pre- and post-test responses of the medical support personnel. Level 3 was addressed in this study by comparing the scored developmental screening tools of the medical support personnel to those of the expert scorer.

Manuscript Three was presented in Chapter Four, and qualitatively reported the experience of medical support personnel's learning of a newly acquired skill, and the application of this skill in clinical practice. Analysis of medical support personnel's reflections on their experience with the educational intervention and application of the information presented in the intervention resulted in four main categories: "Acceptability of the Training"; "Enablers to Implementation"; "Obstacles/Barriers to Implementation"; and "Evidence of Impact". First, study participants reported that the educational intervention was acceptable and informative, and aided in their understanding of developmental screening. Study participants also offered insight into aspects of the intervention and subsequent practice that enabled them to implement developmental 
screening in clinical practice. Time, poor communication between clinic staff, and interpretation of caregiver report of developmental concerns were all indicated as barriers to implementation. Finally, the interviews revealed that participants felt that their role in the implementation of developmental screening had a positive impact on helping to identify children with, or at risk for, developmental delays. Using Kirkpatrick's model as a guide throughout the study, special attention was given to the personal accounts of medical support personnel that corresponded to Levels 1 (Reaction) and 4 (Results) of Kirkpatrick's model during analysis of the data. While many important themes emerged though analysis of the qualitative data, most notably were the participants' reactions to the training, and their self-report of the impact on patient care. Report of impact of the educational intervention on both was positive at both levels of the model.

\section{Implications for Practice}

\section{The Expanding Roles of Medical Support Personnel}

This project provides valuable information on the feasibility of incorporating the administration and scoring of a standardized developmental screening tool by medical support personnel into pediatric primary care practice. Additionally, it also provides insight into how this new role for medical support personnel would incorporate into the workflow of providers and staff. While this project does not provide step-by-step instructions on implementation, it does provide guidance and points of consideration for implementation in other practice settings. This point cannot be emphasized enough, as the work roles of medical support personnel in healthcare settings are expanding. With developments in medical technology, a push toward evidence-based, patient-centered care, and the need to increase access to primary care, a transformation in healthcare 
delivery is occurring nationally (Bodenheimer et al., 2014). There are currently more than 591,000 medical assistants in the United States, with the Bureau of Labor Statistics projecting 138,900 new medical assistant jobs within the next decade (Chapman et al., 2015). On average, this group is paid about \$15.01 per hour (Chapman et al., 2015). Medical assistants are well positioned to help address challenges in the health care delivery system including improving access to care while reducing overall cost. This study's findings align with this perspective, and support the use of medical support personnel administering and scoring a standardized developmental screening tool. This study provided a potential solution to a problem in pediatric primary care. The model used in this study can be generalized to medical practice settings.

\section{Effectiveness of Educational Interventions}

This study also provides support for the use of educational interventions to positively impact the knowledge, attitude, and practice of medical support personnel. The intervention in this study addressed all four level of Kirkpatrick's four level model of evaluation. The model's four levels are: (1) Reaction; (2) Learning; (3) Behavior; and (4) Results. Level one includes assessment of training participants' reaction to the training program. In practice, measures at this level are most commonly directed at assessing trainees' affective responses to the quality (i.e. satisfaction with the instructor) or the relevance (i.e. work-related utility) of training (Kirkpatrick, 1976). In this study, this was reported and measured qualitatively through in-depth interviews. Learning measures, level two, are quantifiable indicators of the learning that has taken place during the course of the training (Kirkpatrick, 1976). In this study, this was reported quantitatively, through the pre- and post-test measures. Level three, behavior outcomes, address either 
the extent to which knowledge and skills gained in training are applied on the job or results in increased job-related performance (Kirkpatrick, 1976). In this study, this was reported quantitatively through the comparison of the scored screeners by the medical support personnel to those of the expert scorer. Lastly, level four outcomes are intended to provide some measure of the impact that training had on broader organizational goals and objectives (i.e. improved clinical outcomes; improved patient experience; enhanced efficiency; profitability) (Kirkpatrick, 1976). In this study, this was measured qualitatively by self-report. This is important, because it is believed that the intervention in this study is the first of its kind to address all four levels of the model. Replication of this study is possible.

\section{Limitations}

There are several limitations of this study which need to be considered. First, this project focused on implementation of a developmental screening tool by medical support personnel for three urban pediatric clinics within a large academic healthcare organization, University of Louisville Pediatrics. This approach tailored the intervention to the workflow, needs, and barriers specific to these practices. Since each pediatric practice has its own workflow and set of needs, the thoughts on implementation of developmental screening by this group, although helpful for some of the practices, may not be generalizable to other practices.

A second limitation of this study is the small sample size $(n=13)$. Although it was intended that all medical support personnel at the three pediatric practices would enroll in the study and participate fully until study conclusion, attrition occurred, reducing the total number of study participants. As a result, some statistical analyses 
were determined to be inconclusive. A larger sample size would generate more robust study findings.

Another important limitation of this study is the lack of a control group that received no educational intervention. A stronger study design would add to the strength of this study's findings, and draw more concrete conclusions about the impact of the educational intervention on medical support personnel's knowledge to administer and score a standardized developmental screening tool.

A final limitation of this study is the clinical outcome measure - identification and referral of more children to early intervention services was not targeted. Given the short timeline of this study, it was not possible to determine if more children were referred to early intervention services following the implementation of the medical support personnel completing the developmental screening. Due to the logistic constraints of this study, this finding was not able to be reported. Repeating this study on a larger scale, and longitudinally, would allow for this conclusion to be made.

\section{Conclusion}

It is known that early detection and intervention of developmental disabilities is necessary to improve long-term academic and behavioral outcomes (Sices, Stancin, Kirchner, \& Bauchner, 2009). Developmental screening tools such as the PEDS can increase early detection of these disabilities. Barriers to implementation of developmental screening tools have been well documented (Halfon et al., 2004; Sand et al., 2005; Sices

et al., 2004). This study offered a solution to this problem. Using a mixed methods study design, incorporating both a before-and-after study measure as well as in-depth 
interviews with medical support personnel, this study provides evidence on the effectiveness of an educational intervention to improve the knowledge of medical support personnel to administer and score a developmental screening tool. This evidence was demonstrated by the significantly increased knowledge level of participants after the implementation of the educational intervention. The study also provides support for the knowledge gained from the educational training that resulted in the transfer of learning to the LPN's clinical practice. This educational intervention could be used in the healthcare nationally to address the educational needs of medical support personnel on developmental screening. Future effort is needed to optimize the use of this type of training with other educational strategies such as simulation training, and to evaluate the impact of this learning strategy on patient outcomes longitudinally, and with a larger group of medical support personnel.

This study provides valuable information on the feasibility of medical support personnel administering and scoring the PEDS developmental screening in pediatric primary care settings. Additionally, it provides insight into how this practice could be incorporated into the workflow of providers and staff. Ultimately, the research agenda targeting educational interventions for medical support personnel should focus on whether knowledge generated through the trainings is able to be re-contextualized into clinical practice, and influence sustained clinical behavior change and patient outcomes. The work in training medical support personnel on new job skills is just beginning. The challenges and complexities inherent when conducting research with a multi-disciplinary, multi-phase process, including patient care will be demanding, but necessary for the future. 


\section{REFERENCES}

Allen, S. G., Berry, A. D., Brewster, J. A., Chalasani, R. K., \& Mack, P. K. (2010). Enhancing developmentally oriented primary care: an Illinois initiative to increase developmental screening in medical homes. Pediatrics, 126 Suppl 3, S160-164. doi:10.1542/peds.2010-1466K

American Academy of Pediatrics. (2006). Identifying infants and young children with developmental disorders in the medical home: an algorithm for developmental surveillance and screening (1098-4275 (Electronic) 0031-4005 (Linking)).

Retrieved from https://www.ncbi.nlm.nih.gov/pubmed/16818591 http://pediatrics.aappublications.org/content/pediatrics/118/1/405.full.pdf

Aylward, G. P. (2009). Developmental screening and assessment: what are we thinking? J Dev Behav Pediatr, 30(2), 169-173. doi:10.1097/DBP.0b013e31819f1c3e

Baker, R., Camosso-Stefinovic, J., Gillies, C., Shaw, E. J., Cheater, F., Flottorp, S., \& Robertson, N. (2010). Tailored interventions to overcome identified barriers to change: effects on professional practice and health care outcomes. Cochrane Database Syst Rev(3), CD005470. doi:10.1002/14651858.CD005470.pub2

Bell, D. S., Harless, C. E., Higa, J. K., Bjork, E. L., Bjork, R. A., Bazargan, M., \& Mangione, C. M. (2008). Knowledge retention after an online tutorial: a randomized educational experiment among resident physicians. J Gen Intern Med, 23(8), 1164-1171. doi:10.1007/s11606-008-0604-2

Berenson, A. B., Rahman, M., Hirth, J. M., Rupp, R. E., \& Sarpong, K. O. (2015). A brief educational intervention increases providers' human papillomavirus vaccine knowledge. Hum Vaccin Immunother, 11(6), 1331-1336. doi:10.1080/21645515.2015.1022691

Bernier, K. M., Strobel, M., \& Lucas, R. (2018). Assessing the Effect of an Educational Intervention on Nurses' and Patient Care Assistants' Comprehension and Documentation of Functional Ability in Pediatric Patients with Sickle Cell Disease. J Pediatr Nurs. doi:10.1016/j.pedn.2018.04.001

Bitsko, R. H., Holbrook, J. R., Robinson, L. R., Kaminski, J. W., Ghandour, R., Smith, C., Peacock, G. (2016). Health Care, Family, and Community Factors Associated with Mental, Behavioral, and Developmental Disorders in Early Childhood United States, 2011-2012. MMWR Morb Mortal Wkly Rep, 65(9), 221-226. doi:10.15585/mmwr.mm6509a1 
Bodenheimer, T., Willard-Grace, R., \& Ghorob, A. (2014). Expanding the roles of medical assistants: who does what in primary care? JAMA Intern Med, 174(7), 1025-1026. doi:10.1001/jamainternmed.2014.1319

Bowen, D. J., Kreuter, M., Spring, B., Cofta-Woerpel, L., Linnan, L., Weiner, D., Fernandez, M. (2009). How we design feasibility studies. Am J Prev Med, 36(5), 452-457. doi:10.1016/j.amepre.2009.02.002

Boyle, C. A., Boulet, S., Schieve, L. A., Cohen, R. A., Blumberg, S. J., Yeargin-Allsopp, M., . . Kogan, M. D. (2011). Trends in the prevalence of developmental disabilities in US children, 1997-2008. Pediatrics, 127(6), 1034-1042. doi:10.1542/peds.2010-2989

Bradley, R., Burchinal, M., \& Casey, P. (2001). Early intervention: The moderating role of the home environment. Applied Developmental Science, 5, 2-8.

Braun, V., \& Clarke, V. (2006). Using thematic analysis in psychology. Qualitative Research in Psychology, 3, 77-101.

Bright, M. A., Zubler, J., Boothby, C., \& Whitaker, T. M. (2019). Improving Developmental Screening, Discussion, and Referral in Pediatric Practice. Clin Pediatr (Phila), 9922819841017. doi:10.1177/0009922819841017

Brinkman, S., \& Kvale, S. (2015). Interviews: Learning the craft of qualitative research interviewing. New York: Springer.

Bryan, T. J., Estrada, C. A., Castiglioni, A., \& Snyder, E. D. (2015). Impact of an educational intervention on provider knowledge, attitudes, and comfort level regarding counseling women ages 40-49 about breast cancer screening. $J$ Multidiscip Healthc, 8, 209-216. doi:10.2147/JMDH.S80337

Centers for Disease Control and Prevention. (2015, September 8, 2015). Developmental Disabilities. Retrieved from http://www.cdc.gov/ncbddd/developmentaldisabilities/index.htmlCenters for Disease Control and Prevention. (2018). Developmental Disabilities Retrieved from https://www.cdc.gov/ncbddd/developmentaldisabilities/facts.html

Chapman, S. A., Marks, A., \& Dower, C. (2015). Positioning medical assistants for a greater role in the era of health reform. Academic Medicine, 90(10), 1347-1352. doi:10.1097/ACM.0000000000000775

Charman, T., Howlin, P., Aldred, C., Baird, G., Degli Espinosa, F., Diggle, T., .. . Wolke, D. (2003). Research into early intervention for children with autism and related disorders: methodological and design issues. Report on a workshop funded by the Wellcome Trust, Institute of Child Health, London, UK, November 2001. Autism, 7(2), 217-225. 
Cooley, W. C., \& McAllister, J. W. (2004). Building medical homes: improvement strategies in primary care for children with special health care needs. Pediatrics, 113(5 Suppl), 1499-1506.

Creswell, J. (2009). Research Design: Qualitative, Quantitative, and Mixed Methods Approaches (3rd ed.). Los Angeles, CA: SAGE Publications, Inc.

Creswell, J. (2013). Qualitative Inquiry \& Research Design: Choosing Among Five Approaches (3rd ed.). Los Angeles, CA: SAGE Publications, Inc.

Daniel, K. L., Prue, C., Taylor, M. K., Thomas, J., \& Scales, M. (2009). 'Learn the signs. Act early': a campaign to help every child reach his or her full potential. Public Health, 123 Suppl 1, e11-16. doi:10.1016/j.puhe.2009.06.002

Davis, D. W., Honaker, S. M., Jones, V. F., Williams, P. G., Stocker, F., \& Martin, E. (2012). Identification and management of behavioral/mental health problems in primary care pediatrics: perceived strengths, challenges, and new delivery models. Clin Pediatr (Phila), 51(10), 978-982. doi:10.1177/0009922812441667

Djuric, Z., Segar, M., Orizondo, C., Mann, J., Faison, M., Peddireddy, N., Locke, A. (2017). Delivery of Health Coaching by Medical Assistants in Primary Care. J Am Board Fam Med, 30(3), 362-370. doi:10.3122/jabfm.2017.03.160321

Douglas, T. M., Levine, A. R., Olivieri, P. P., McCurdy, M. T., Papali, A., Zubrow, M. T., ... Verceles, A. C. (2019). Brief training increases nurses' comfort using teleultrasound: A feasibility study. Intensive Crit Care Nurs, 51, 45-49. doi:10.1016/j.iccn.2018.11.004

Drotar, D., Stancin, T., Dworkin, P. H., Sices, L., \& Wood, S. (2008). Selecting developmental surveillance and screening tools. Pediatr Rev, 29(10), e52-58. doi:10.1542/pir.29-10-e52

Ferrante, J. M., Shaw, E. K., Bayly, J. E., Howard, J., Quest, M. N., Clark, E. C., \& Pascal, C. (2018). Barriers and Facilitators to Expanding Roles of Medical Assistants in Patient-Centered Medical Homes (PCMHs). J Am Board Fam Med, 31(2), 226-235. doi:10.3122/jabfm.2018.02.170341

Ferrer, R. L., Mody-Bailey, P., Jaen, C. R., Gott, S., \& Araujo, S. (2009). A medical assistant-based program to promote healthy behaviors in primary care. Ann Fam Med, 7(6), 504-512. doi:10.1370/afm.1059

Glanz, K. R., B.; and Viswanath, K.;. (2008). Health Behavior and Health Education: Theory, Research, and Practice (4th ed.). San Fransisco, CA: Jossey-Bass.

Glascoe, F. P. (2005). Screening for developmental and behavioral problems. Ment Retard Dev Disabil Res Rev, 11(3), 173-179. doi:10.1002/mrdd.20068 
Glascoe, F. P., \& Squires, J. K. (2013). Quality developmental screenings are essential to quality surveillance. Pediatrics, 132(5), e1450. doi:10.1542/peds.2013-2720B

Golnik, A., Ireland, M., \& Borowsky, I. W. (2009). Medical homes for children with autism: a physician survey. Pediatrics, 123(3), 966-971. doi:10.1542/peds.20081321

Guevara, J. P., Gerdes, M., Localio, R., Huang, Y. V., Pinto-Martin, J., Minkovitz, C. S., Pati, S. (2013). Effectiveness of developmental screening in an urban setting. Pediatrics, 131(1), 30-37. doi:10.1542/peds.2012-0765

Halfon, N., Houtrow, A., Larson, K., \& Newacheck, P. W. (2012). The changing landscape of disability in childhood. Future Child, 22(1), 13-42.

Halfon, N., Regalado, M., Sareen, H., Inkelas, M., Reuland, C. H., Glascoe, F. P., \& Olson, L. M. (2004). Assessing development in the pediatric office. Pediatrics, 113(6 Suppl), 1926-1933.

Hamilton, S. (2006). Screening for developmental delay: reliable, easy-to-use tools. $J$ Fam Pract, 55(5), 415-422.

Healthy People 2020. Early and Middle Childhood. Retrieved from https://www.healthypeople.gov/2020/topics-objectives

Honigfeld, L., Chandhok, L., \& Spiegelman, K. (2012). Engaging pediatricians in developmental screening: the effectiveness of academic detailing. J Autism Dev Disord, 42(6), 1175-1182. doi:10.1007/s10803-011-1344-4

Hornman, J., Kerstjens, J. M., de Winter, A. F., Bos, A. F., \& Reijneveld, S. A. (2013). Validity and internal consistency of the Ages and Stages Questionnaire 60-month version and the effect of three scoring methods. Early Hum Dev, 89(12), 10111015. doi:10.1016/j.earlhumdev.2013.08.016

Jimenez, M. E., Fiks, A. G., Shah, L. R., Gerdes, M., Ni, A. Y., Pati, S., \& Guevara, J. P. (2014). Factors associated with early intervention referral and evaluation: a mixed methods analysis. Acad Pediatr, 14(3), 315-323. doi:10.1016/j.acap.2014.01.007

Keil, A., Breunig, C., Fleischfresser, S., \& Oftedahl, E. (2014). Promoting routine use of developmental and autism-specific screening tools by pediatric primary care clinicians. WMJ, 113(6), 227-231.

Kentucky Cabinet for Health and Family Services. (2016). Retrieved from http://chfs.ky.gov/dph/mch/default.htm

King, T. M., Tandon, S. D., Macias, M. M., Healy, J. A., Duncan, P. M., Swigonski, N. L., Lipkin, P. H. (2010). Implementing developmental screening and referrals: 
lessons learned from a national project. Pediatrics, 125(2), 350-360.

doi:10.1542/peds.2009-0388

Kirkpatrick, D. (1976). Evaluation of training and development handbook: a guide to human resources. New York: McGraw-Hill.

Ladden, M. D., Bodenheimer, T., Fishman, N. W., Flinter, M., Hsu, C., Parchman, M., \& Wagner, E. H. (2013). The emerging primary care workforce: preliminary observations from the primary care team: learning from effective ambulatory practices project. Acad Med, 88(12), 1830-1834. doi:10.1097/ACM.0000000000000027

Liaw, S. Y., Wong, L. F., Lim, E. Y., Ang, S. B., Mujumdar, S., Ho, J. T., .. . Ang, E. N. (2016). Effectiveness of a Web-Based Simulation in Improving Nurses' Workplace Practice With Deteriorating Ward Patients: A Pre- and Postintervention Study. J Med Internet Res, 18(2), e37. doi:10.2196/jmir.5294

Limbos, M. M., \& Joyce, D. P. (2011). Comparison of the ASQ and PEDS in screening for developmental delay in children presenting for primary care. J Dev Behav Pediatr, 32(7), 499-511. doi:10.1097/DBP.0b013e31822552e9

Lipkin, P. H., \& Schertz, M. (2008). Early intervention and its efficacy Baltimore, MD: Brookes.

Long, C. O. (2013). Pain management education in long-term care: it can make a difference. Pain Manag Nurs, 14(4), 220-227. doi:10.1016/j.pmn.2011.04.005

Mackrides, P. S., \& Ryherd, S. J. (2011). Screening for developmental delay. Am Fam Physician, 84(5), 544-549.

Montgomery, L., Benzies, K., \& Barnard, C. (2016). Effects of an Educational Workshop on Pediatric Nurses' Attitudes and Beliefs About Family-Centered Bedside Rounds. J Pediatr Nurs, 31(2), e73-82. doi:10.1016/j.pedn.2015.10.008

Morelli, D. L., Pati, S., Butler, A., Blum, N. J., Gerdes, M., Pinto-Martin, J., \& Guevara, J. P. (2014). Challenges to implementation of developmental screening in urban primary care: a mixed methods study. BMC Pediatr, 14, 16. doi:10.1186/14712431-14-16

Naughton, D., Adelman, A. M., Bricker, P., Miller-Day, M., \& Gabbay, R. (2013). Envisioning new roles for medical assistants: strategies from patient-centered medical homes. Fam Pract Manag, 20(2), 7-12.

Nelson, H. D., Nygren, P., Walker, M., \& Panoscha, R. (2006). Screening for speech and language delay in preschool children: systematic evidence review for the US 
Preventive Services Task Force. Pediatrics, 117(2), e298-319. doi:10.1542/peds.2005-1467

Omachonu, V., Einspurch, N. (2010). Innovation in healthcare delivery systems: A conceptual framework. The Public Sector Innovation Journal, 15(1), 1-20.

Painter, J. E., Borba, C. P., Hynes, M., Mays, D., \& Glanz, K. (2008). The use of theory in health behavior research from 2000 to 2005: a systematic review. Ann Behav Med, 35(3), 358-362. doi:10.1007/s12160-008-9042-y

Pfeifer, P., Vandenhouten, C., Purvis, S., \& Zupanc, T. (2018). The Impact of Education on Certified Nursing Assistants' Identification of Strategies to Manage Behaviors Associated With Dementia. J Nurses Prof Dev, 34(1), 26-30. doi:10.1097/NND.0000000000000418

Pinto-Martin, J. A., Dunkle, M., Earls, M., Fliedner, D., \& Landes, C. (2005). Developmental stages of developmental screening: steps to implementation of a successful program. Am J Public Health, 95(11), 1928-1932. doi:10.2105/AJPH.2004.052167

Radecki, L., Sand-Loud, N., O'Connor, K. G., Sharp, S., \& Olson, L. M. (2011). Trends in the use of standardized tools for developmental screening in early childhood: 2002-2009. Pediatrics, 128(1), 14-19. doi:10.1542/peds.2010-2180

Rice, C. E., Naarden Braun, K. V., Kogan, M. D., Smith, C., Kavanagh, L., Strickland, B., Prevention. (2014). Screening for developmental delays among young children--National Survey of Children's Health, United States, 2007. MMWR Suppl, 63(2), 27-35.

Roulston, K. (2010). Considering quality in qualitative interviewing. Qualitative Research, 10(2), 199-228.

Rydz, D., Srour, M., Oskoui, M., Marget, N., Shiller, M., Birnbaum, R., ... Shevell, M. I. (2006). Screening for developmental delay in the setting of a community pediatric clinic: a prospective assessment of parent-report questionnaires. Pediatrics, 118(4), e1178-1186. doi:10.1542/peds.2006-0466

Sameroff, A. J. (2000). Developmental systems and psychopathology. Dev Psychopathol, 12(3), 297-312.

Sand, N., Silverstein, M., Glascoe, F. P., Gupta, V. B., Tonniges, T. P., \& O'Connor, K. G. (2005). Pediatricians' reported practices regarding developmental screening: do guidelines work? Do they help? Pediatrics, 116(1), 174-179. doi:10.1542/peds.2004-1809

Schonwald, A., Huntington, N., Chan, E., Risko, W., \& Bridgemohan, C. (2009). Routine developmental screening implemented in urban primary care settings: more 
evidence of feasibility and effectiveness. Pediatrics, 123(2), 660-668.

doi:10.1542/peds.2007-2798

Sheldrick, R. C., \& Perrin, E. C. (2009). Surveillance of children's behavior and development: practical solutions for primary care. J Dev Behav Pediatr, 30(2), 151-153. doi:10.1097/DBP.0b013e31819f1bfb

Sices, L., Drotar, D., Keilman, A., Kirchner, H. L., Roberts, D., \& Stancin, T. (2008). Communication about child development during well-child visits: impact of parents' evaluation of developmental status screener with or without an informational video. Pediatrics, 122(5), e1091-1099. doi:10.1542/peds.2008-1773

Sices, L., Feudtner, C., McLaughlin, J., Drotar, D., \& Williams, M. (2003). How do primary care physicians identify young children with developmental delays? A national survey. J Dev Behav Pediatr, 24(6), 409-417.

Sices, L., Feudtner, C., McLaughlin, J., Drotar, D., \& Williams, M. (2004). How do primary care physicians manage children with possible developmental delays? A national survey with an experimental design. Pediatrics, 113(2), 274-282.

Sices, L., Stancin, T., Kirchner, L., \& Bauchner, H. (2009). PEDS and ASQ developmental screening tests may not identify the same children. Pediatrics, 124(4), e640-647. doi:10.1542/peds.2008-2628

Silverstein, M., Sand, N., Glascoe, F. P., Gupta, V. B., Tonniges, T. P., \& O'Connor, K. G. (2006). Pediatrician practices regarding referral to early intervention services: is an established diagnosis important? Ambul Pediatr, 6(2), 105-109. doi:10.1016/j.ambp.2005.09.003

Smeekens, A. E. F. N., Broekhuijsen-van Henten, D. M., Sittig, J. S., Russel, I. M. B., ten Cate, O. T. J., Turner, N. M., \& van de Putte, E. M. (2011). Successful e-learning programme on the detection of child abuse in Emergency Departments: a randomised controlled trial. Archives of Disease in Childhood, 96(4), 330-334. doi:10.1136/adc.2010.190801

Titler, M. G. (2010). Translation science and context. Res Theory Nurs Pract, 24(1), 3555.

Wisdom, J. P., Chor, K. H., Hoagwood, K. E., \& Horwitz, S. M. (2014). Innovation adoption: a review of theories and constructs. Adm Policy Ment Health, 41(4), 480-502. doi:10.1007/s10488-013-0486-4

World Health Organization. (2008). A Guide to Developing Knowledge, Attitude and Practice Surveys. Retrieved from

Yeung, L. F., Shapira, S. K., Coates, R. J., Shaw, F. E., Moore, C. A., Boyle, C. A., . . Prevention. (2014). Rationale for periodic reporting on the use of selected clinical 
preventive services to improve the health of infants, children, and adolescents-United States. MMWR Suppl, 63(2), 3-13.

Zablotsky, B., Black, L. I., \& Blumberg, S. J. (2017). Estimated Prevalence of Children With Diagnosed Developmental Disabilities in the United States, 2014-2016. NCHS Data Brief(291), 1-8.

Zuckerman, B., Stevens, G. D., Inkelas, M., \& Halfon, N. (2004). Prevalence and correlates of high-quality basic pediatric preventive care. Pediatrics, 114(6), 1522-1529. doi:10.1542/peds.2004-0635 


\section{APPENDIX A}

Participant \#:

Date:

\section{Developmental Screening in Pediatric Primary Care}

We wish to learn about your knowledge, attitude, and practices regarding developmental screening. We hope to understand your needs and the best way to bring information to you, as well as any barriers to completing the screening process. The information you provide will be used to improve the screening process and patient care. This survey consists of 16 questions and takes approximately 5 minutes to complete.

Your answers will not be released to anyone and will remain confidential. Your name will not be written on the questionnaire or be kept in any other records. Your participation is voluntary and you may choose to stop completing the questionnaire at any time.

Thank vou for vour ascistance

\section{Please write-in or mark the most appropriate response to the following questions:}

1. How old are you?

2. What is your level of health professional education?

$\square \quad$ Medical Assistant (MA)

$\square \quad$ Certified Nurse Assistant (CNA)

$\square \quad$ Licensed Practical Nurse (LPN)

$\square \quad$ Other medical support personnel (please specify)

3. How long have you been practicing in your current role?

4. Have you ever received formal training on screening for developmental disabilities?

$\square \quad$ Yes

$\square \quad$ No 
Indicate how you would respond to each statement. Agree or disagree by circling one of the following:

$\mathrm{SD}=$ Strongly Disagree; $\mathrm{D}=$ Disagree; $\mathrm{N}=$ Neutral; $\mathrm{A}=$ Agree; $\mathrm{SA}=$ Strongly Agree

\begin{tabular}{|c|c|c|c|c|c|}
\hline & $\begin{array}{l}\text { Strongly } \\
\text { Disagree }\end{array}$ & Disagree & Neutral & Agree & Strongly Agree \\
\hline $\begin{array}{l}\text { 5. Formal developmental screening is beneficial in } \\
\text { identifying developmental disabilities in young children. }\end{array}$ & SD & D & $\mathbf{N}$ & A & SA \\
\hline $\begin{array}{l}\text { 6. Completing formal developmental screening at well- } \\
\text { child visits is an important step in connecting young } \\
\text { children with early intervention services. }\end{array}$ & SD & D & $\mathbf{N}$ & A & SA \\
\hline $\begin{array}{l}\text { 7. It is important to identify children with } \\
\text { developmental disabilities early so that they can get the } \\
\text { help they need to minimize later adverse outcomes. }\end{array}$ & SD & D & $\mathbf{N}$ & A & SA \\
\hline $\begin{array}{l}\text { 8. I am comfortable administering the Parents' } \\
\text { Evaluation of Developmental Status (PEDS) to families } \\
\text { when they bring their children to well-child visits. }\end{array}$ & SD & D & $\mathbf{N}$ & A & SA \\
\hline $\begin{array}{l}\text { 9. I am comfortable scoring the Parents' Evaluation of } \\
\text { Developmental Status (PEDS). }\end{array}$ & SD & D & $\mathbf{N}$ & A & SA \\
\hline $\begin{array}{l}\text { 10. Thinking about administering the Parents' } \\
\text { Evaluation of Developmental Status (PEDS) makes me } \\
\text { feel worried and uneasy. }\end{array}$ & SD & D & $\mathbf{N}$ & A & SA \\
\hline
\end{tabular}




\begin{tabular}{|c|c|c|c|c|c|}
\hline $\begin{array}{l}\text { 11. Thinking about scoring the Parents' Evaluation of } \\
\text { Developmental Status (PEDS) makes me feel worried } \\
\text { and uneasy. }\end{array}$ & SD & D & $\mathbf{N}$ & A & SA \\
\hline $\begin{array}{l}\text { 12. I feel well informed about the administration of the } \\
\text { Parents' Evaluation of Developmental Status (PEDS). }\end{array}$ & SD & D & $\mathbf{N}$ & A & SA \\
\hline $\begin{array}{l}\text { 13. I feel well informed about the scoring of the } \\
\text { Parents' Evaluation of Developmental Status (PEDS). }\end{array}$ & SD & D & $\mathbf{N}$ & A & SA \\
\hline $\begin{array}{l}\text { 14. Completing educational trainings at work empowers } \\
\text { me to do my job better. }\end{array}$ & SD & D & $\mathbf{N}$ & $A$ & SA \\
\hline $\begin{array}{l}\text { 15. Completing educational trainings at work helps me } \\
\text { learn new skills at work. }\end{array}$ & SD & D & $\mathbf{N}$ & A & SA \\
\hline $\begin{array}{l}\text { 16. My role at work has a positive impact on identifying } \\
\text { developmental problems in young children. }\end{array}$ & SD & D & $\mathbf{N}$ & $A$ & SA \\
\hline
\end{tabular}




\section{APPENDIX B}

Interview Protocol Questions

\section{Research Question \\ 1. What is the experience of medical} support personnel in learning and applying a newly acquired skill in clinical practice?

\section{Interview Questions}

Level 1: Reaction: How participants react to the intervention. Was it acceptable?

- Tell me about your experience participating in the training about developmental screening.

- What was the most confusing or annoying thing about the training? Why do you feel that way?

- What worked well for you? Why did that work well for you?

- What did you like the best about the training?

- What would you most want to change about the training?

- What did you expect from the training?

Level 2: Learning: Effect on knowledge, skills, and attitudes about developmental screening. What was acquired?

- Tell me about the parts of the training that helped inform your knowledge about screening.

- Tell me about your experience with the scoring guide.

- Based on your experience, do you feel more confident in administering the PEDS? If so, what factors do you think most help you know how to administer the PEDS?

- Based on your experience, do you feel more confident in scoring the PEDS? If so, what factors do you think most help you know how to score the PEDS?

- How do your initial assumptions about administering the PEDS compare to the actual experience of administering the tool?

- How do your initial assumptions about scoring the PEDS compare to the actual experience of scoring the tool? 


\begin{tabular}{|l|l|}
\hline $\begin{array}{l}\text { Level 3: Behavior: Extent to which behavior has } \\
\text { changed. How was the learning applied in practice? }\end{array}$ \\
\hline $\begin{array}{l}\text { Did you encounter any obstacles administering the } \\
\text { PEDS screener? If so, how did you overcome obstacles } \\
\text { in administering the PEDS screener? }\end{array}$ \\
Did you encounter any obstacles scoring the PEDS \\
screener? If so, how did you overcome obstacles in \\
scoring the PEDS screener? \\
Was there ever a time that you needed to ask a \\
colleague a question for clarification of the procedure \\
using the PEDS screener? If so, whom did you ask? \\
How did this person help you? \\
What kinds of questions did you have when \\
administering the PEDS? \\
What kinds of questions did you have when scoring \\
the PEDS? \\
$\begin{array}{l}\text { Level 4: Results: What was the effect of the training } \\
\text { on patient care? }\end{array}$ \\
How did the training fit into your work? \\
How might this change the way that you work in the \\
future? \\
What kind of support do you think is important for you \\
to continue to administer the PEDS? \\
What kind of support do you think is important for you \\
What are your suggestions for how to make sure that \\
young children are identified with developmental \\
disabilities as early as possible?
\end{tabular}




\title{
CURRICULUM VITAE
}

\author{
Leslie C. Lopez
}

\section{EDUCATION}

Doctor of Philosophy in Public Health Sciences (ABD)

January 2011-present

University of Louisville, Louisville, KY

Department of Public Health and Informational Sciences

Specialization: Health Promotion and Behavioral Sciences

Master of Science in Speech-Language Pathology

August 2004

Southern Illinois University, Carbondale, Illinois

Summa Cum Laude

Bachelor of Science in Communication Sciences and Disorders December 2002

Minor, Psychology; Teacher Certification Track

Southern Illinois University, Carbondale, Illinois

Summa Cum Laude

\section{PROFESSIONAL EXPERIENCE}

\section{Clinical Faculty, Instructor I}

August 2017-present

\author{
University of South Florida \\ Tampa, FL
}

- Instructor of Diagnostic Principles and Practices (SPA5552), a required, graduate-level course for all CSD Master of Science students, focusing on the assessment process (standardized and informal evaluation measures) of varying communication disorders across the lifespan, and psychometrics

- Supervisor of graduate-level students in clinical practicum at The University of South Florida Speech-Language-Hearing Clinic (first-year and advanced practicum students; 6-7 students per semester)

- Supervisor of graduate-level students in diagnostic clinical practicum at Hillsborough County Public School system (first-year and advanced practicum students; 6-7 students per semester)

- Simucase Instructor - simulated, alternative clinical education for students in higher education

- Provide service to the department, college, and profession 


\section{Diagnostician/Speech-Language}

Pathologist, Senior/Clinical Instructor University of Louisville, Louisville, KY

July 2006-June 2017

Weisskopf Child Evaluation Center

- Evaluate children from across the state of Kentucky with a variety of developmental and genetic disorders aged birth to 21 years as a part of an interdisciplinary diagnostic team (developmental-behavioral pediatrician/psychologist/occupational therapist/genetics/social work)

- Provide clinical instruction and supervision to graduate student clinicians (1-2 students per semester) providing evaluation and treatment to children with varying communication disorders

- Provide direct treatment to preschool and school-aged children with developmental language disorders and language-based learning disorders, articulation and phonological disorders, Autism Spectrum Disorder, Childhood Apraxia of Speech, fluency disorders, and children with comorbid developmental disorders such as intellectual disability, ADHD, anxiety, and social communication disorder

- Communicate with school districts and health care agencies state-wide to assist in services coordination

\section{Speech-Language Pathologist}

January 2009-March 2017
RehabCare/Kindred Hospital Louisville Louisville, $K Y$

- Provide dysphagia management, cognitive-linguistic skills training, receptiveexpressive language treatment, and Passy-Muir speaking valve (PMV) training to adult patients in a long-term care hospital and patients in rehabilitation/skilled nursing facilities

- Develop treatment plans, provide staff and caregiver education, build relationships with patient families to maintain carryover of learned skills, attend interdisciplinary care plan meetings, and provide therapeutic interventions in an interdisciplinary team environment

\section{Speech-Language Pathologist}

December 2010-December 2016
Home of the Innocents

Louisville, $K Y$

- Implement skilled, patient-focused therapy to manage feeding, functional language skills development, and Passy-Muir speaking valve training to medically fragile children aged birth to 21 years in a pediatric skilled nursing facility, many of whom require ventilator support

- Coordinate care in an interdisciplinary team environment, develop plans of care, complete documentation, and attend annual skills validation trainings 
Speech-Language Pathologist

August 2004-June 2006
Special School District of St. Louis County

St. Louis, $M O$

- Perform speech and language evaluation and treatment for school-aged children with a wide range of communication disorders including Specific Language Impairment, intellectual disability, Autism Spectrum Disorder, and other health impairment

- Provide case management services for students with primary speech-language impairments, including writing Individualized Education Plans (IEP), leading IEP team meetings, monitoring student placement and progress across academic subjects, and performing periodic re-evaluation

- Assist in the selection of augmentative and alternative communication for students who are primarily nonverbal communicators, or who have significant intelligibility concerns

- Provide supports for school personnel including formal and informal training sessions and professional development activities

\section{EDUCATIONAL ACTIVITIES/SERVICE}

- Language in Infants through Preschoolers Topic Committee member for the 2019 ASHA Convention

- ASHA MARC mentee (MARC 2018-19 cohort)

- USF CSD Department Chair Committee search member (Fall 2018-present)

- USF CSD Instructor Annual Evaluations Committee member (Spring 2019present)

- Board Certified Specialist in Child Language (application in process; Phase I)

- NSSLHA co-sponsor (2017-present)

- USF Online Course Instructor Certification (completed Spring 2018)

- FLASHA Praxis Bowl coach (2018)

- Coordinator of Diagnostic Practicum rotation for graduate student clinicians in Hillsborough County Public Schools (2017-present)

- Graduate School Alliance Program member with Western Psychological Services (WPS) (2018)

- Instructor for Hanen More Than Words parent coaching groups for caregivers of children with Autism Spectrum Disorder and social communication disorders (2011, 2012); assist in securing funding to run programs; collaborate with BCBA clinicians at the Kentucky Autism Training Center (KATC)

- Provide didactic education for graduate clinicians and medical residents rotating through clinic on topics related to early intervention, language development, and evidenced-based interventions for preschool-aged children (2012-2017)

- Determine eligibility and provision of speech-language intervention for children aged birth to three (statewide) requesting services through First Steps, Kentucky's Early Intervention System (2012-2017)

- Determine appropriate team member(s) to provide evaluation to children aged three to five referred to the Weisskopf Child Evaluation Center based on physician referral and parent-completed pre-evaluation forms (2015-2017) 


\section{RESEARCH EXPERIENCE}

Dissertation

"Determining the Effect of an Educational Intervention on Medical Support Personnel's

Knowledge to Administer a Standardized Developmental Screening Tool”

University of Louisville

Richard Wilson, DHSc, Committee Chair

\section{Research Assistant}

Coal Ash and Community Health

University of Louisville

Kristina Zierold, PhD, Principal Investigator

- Sought to determine not only health behaviors and perceptions of community residents living in close proximity to a coal burning power plant, but also investigate their beliefs that the children in their community have higher incidence and prevalence rates of developmental disabilities including ASD, ADHD, and intellectual disability

- Completed community engagement activities, including neighborhood canvassing; assisted in writing focus group guides and follow-up questions; co-led focus groups; analyzed focus group transcription and coded data for themes

Policy Analyst Assistant

2012

"Reducing the Percentage of Preterm and Low Birth Weight Births

from Maternal Smoking in Kentucky: An Evidence-Based Policy Analysis”,

University of Louisville

Winsor Schmidt, J.D., LL.M., Project Administrator

*Poster presented at Kentucky Public Health Association Convention, 2013

\section{LICENSURE/CERTIFICATION}

American Speech-Language Hearing Association (ASHA) September 2005-present Membership and Certification (CCC) \#12116398

\section{Registered Speech-Language Pathologist}

State of Florida

State of Kentucky

May 2017-present

June 2006-present

\section{The Hanen Centre}

It Takes Two to Talk

2009-present

More Than Words 2010-presnt 
The Picture Exchange Communication System (PECS) 2010

PECS Basic Training

Teacher Certification

State of Missouri

State of Illinois

August 2004-August 2006

August 2004-August 2007

\section{PROFESSIONAL MEMBERSHIPS}

American Speech-Language-Hearing Association (ASHA)

Florida Speech-Language-Hearing Association (FLASHA)

Kentucky Speech-Language-Hearing Association (KYSHA)

Kentucky Public Health Association (KPHA)

\section{SCHOLASTIC/PROFESSIONAL AWARDS}

ASHA ACE Award

Phi Kappa Phi National Honor Society

Golden Key National Honor Society

Sigma Tau Delta English Honor Society

25 Most Distinguished Seniors

Graduate Assistantship, SIU-C
2008,2010

2001-2004

2002

2000-2001

2002

2003-2004

\section{$\underline{\text { References }}$}

Available upon request

Student Assessment of Instruction Reporting (course evaluation reports)

Available upon request

\section{Continuing Education}

Courses completed available upon request 